\title{
Intercomparison of remote-sensing based evapotranspiration algorithms over amazonian forests
}

\author{
José Gomis-Cebolla ${ }^{\mathrm{a}, *}$, Juan Carlos Jimenez ${ }^{\mathrm{a}}$, José Antonio Sobrino ${ }^{\mathrm{a}}$, Chiara Corbari ${ }^{\mathrm{b}}$, \\ Marco Mancini ${ }^{\mathrm{b}}$ \\ ${ }^{\text {a }}$ Global Change Unit, Image Processing Laboratory, University of Valencia, Paterna, Valencia 46010, Spain \\ ${ }^{\mathrm{b}}$ DICA Politecnico di Milano, Piazza Leonardo da Vinci, 32, 20133 Milano, Italy
}

\begin{abstract}
Evapotranspiration (ET) is considered a key variable in the understanding of the Amazonian tropical forests and their response to climate change. Remote-Sensing (RS) based evapotranspiration models are presented as a feasible means in order to provide accurate spatially-distributed ET estimates over this region. In this work, the performance of four commonly used ET RS models was evaluated over Amazonia using Moderate Resolution Imaging Spectroradiometer (MODIS) data. RS models included i) Priestley-Taylor Jet Propulsion Laboratory (PT-JPL), ii) Penman-Monteith MODIS operative parametrization (PM-Mu), iii) Surface Energy Balance System (SEBS), and iv) Satellite Application Facility on Land Surface Analysis (LSASAF). These models were forced using two ancillary meteorological data sources: i) in-situ data extracted from Large-Scale Biosphere-Atmosphere Experiment (LBA) stations (scenario I), and ii) three reanalysis datasets (scenario II), including Modern-Era Retrospective analysis for Research and Application (MERRA-2), European Centre for Medium-range Weather Forecasts (ECMWF) Re-Analysis-Interim (ERA-Interim), and Global Land Assimilation System (GLDAS-2). Performance of algorithms under the two scenarios was validated using in-situ eddy-covariance measurements. For scenario I, PT-JPL provided the best agreement with in-situ ET observations (RMSE $=0.55 \mathrm{~mm} /$ day, $\mathrm{R}=0.88$ ). Neglecting water canopy evaporation resulted in an underestimation of ET measurements for LSASAF. SEBS performance was similar to that of PT-JPL, nevertheless SEBS estimates were limited by the continuous cloud cover of the region. A physically-based ET gap-filling method was used in order to alleviate this issue. PM-Mu tended to overestimate in-situ ET observations. For scenario II, quality assessment of reanalysis input data demonstrated that MERRA-2, ERA-Interim and GLDAS-2 contain biases that impact model perfor-mance. In particular, biases in radiation inputs were found the main responsible of the observed biases in ET estimates. For the region, MERRA-2 tends to overestimate daily net radiation and incoming solar radiation. ERA-Interim tends to underestimate both variables, and GLDAS tends to overestimate daily radiation while under-estimating incoming solar radiation. Discrepancies amongst these reanalysis inputs generally explain the ob-served discrepancies in model spatial and temporal patterns.
\end{abstract}

Keywords:

Amazonian tropical forests

Terrestrial evapotranspiration

MODIS

Reanalysis

\section{Introduction}

The Amazon forest accounting for approximately one-half of the global tropical forest area (Malhi et al., 2008) is one of the world's most extensive natural ecosystems. It is a major source of global evapotranspiration (Harper et al., 2014) and accounts for about 15\% of global terrestrial photosynthesis (Malhi, 2011). It is a main actor in the global water and carbon cycle (Werth and Avissar, 2002). Relatively small changes in the structure, composition and functioning of these forests have shown the potential to affect regional and global climate as pointed out in observational and modelling studies (von Randow et al., 2004). In this context, evapotranspiration being able to link the terrestrial, water, carbon and surface energy exchanges stands out as being a key variable in understanding the functioning of these forests and their response to the changing climate (Cox et al., 2000).

Nevertheless, estimation of tropical evapotranspiration is hindered by the lack of continuous and spatially dense ground-based measurements in the region. Although understanding of Amazonian forest processes has greatly advanced through the establishment of a network of eddy covariance flux towers across the Brazilian Amazon, providing

\footnotetext{
* Corresponding author.

E-mail address: jose.gomis@uv.es (J. Gomis-Cebolla).
} 


\section{Nomenclature}

PET Potential evapotranspiration ( $\mathrm{mm} /$ day)

ET Actual evapotranspiration ( $\mathrm{mm} /$ day)

$\lambda \mathrm{E} \quad$ Latent heat flux $\left(\mathrm{W} / \mathrm{m}^{2}\right)$

$\lambda \mathrm{E}_{\mathrm{c}} \quad$ Canopy transpiration $\left(\mathrm{W} / \mathrm{m}^{2}\right)$

$\lambda E_{s} \quad$ Soil evaporation $\left(W / m^{2}\right)$

$\lambda E_{I} \quad$ Interception $\left(\mathrm{W} / \mathrm{m}^{2}\right)$

$\alpha_{p t} \quad$ Priestley-Taylor coefficient (1.26) (-)

$f_{\text {wet }} \quad$ Relative surface wetness (0-1) (-)

$\Delta \quad$ Slope of saturation-to-vapor pressure curve $\left(\mathrm{PaK}^{-1}\right)$

$\gamma \quad$ Psychometric constant $\left(\mathrm{PaK}^{-1}\right)$

$f_{g} \quad$ Green canopy fraction (0-1) (-)

$f_{M} \quad$ Plant moisture constraint (0-1) (-)

$f_{S M} \quad$ Soil moisture constraint (0-1) (-)

$f_{T} \quad$ Plant temperature constraint (0-1) (-)

$f_{A P A R} \quad$ Fraction of PAR absorbed by green vegetation cover (-)

PAR Photosynthetically Active Radiation $\left(\mathrm{Wm}^{-2}\right)$

$f_{\text {APARmax }}$ Maximum Fapar (-)

$f_{\text {IPAR }} \quad$ Fraction of PAR intercepted by fc (-)

fc Vegetation fraction cover (-)

RH Relative humidity (-)

VPD Water vapour deficit (Pa)

$e_{a} \quad$ Air vapour pressure (Pa)

$e_{s} \quad$ Saturation vapour pressure $(\mathrm{Pa})$

$T_{\text {opt }} \quad$ Optimum plant growth temperature $\left({ }^{\circ} \mathrm{C}\right)$

$\mathrm{T}_{\max } \quad$ Daily maximum temperature $\left({ }^{\circ} \mathrm{C}\right)$

NDVI Normalized Difference Vegetation Index (-)

$\mathrm{NDVI}_{\text {max }}$ Yearly maximum NDVI (-)

LAI Leaf Area Index (-)

SAVI Soil Adjusted Vegetation Index (-)

$R_{n} \quad$ Net radiation $\left(\mathrm{W} / \mathrm{m}^{2}\right)$

$R_{n c}, R_{n s} \quad$ Canopy and soil net radiation $\left(\mathrm{W} / \mathrm{m}^{2}\right)$

$H \quad$ Sensible heat flux $\left(\mathrm{W} / \mathrm{m}^{2}\right)$

G Soil heat flux $\left(\mathrm{W} / \mathrm{m}^{2}\right)$

$\rho \quad$ Air density $\left(\mathrm{kgm}^{-3}\right)$

$c_{p} \quad$ Specific heat at constant pressure $\left(\mathrm{J} \mathrm{kg}^{-1} \mathrm{~K}^{-1}\right)$

$r_{a}^{w c} \quad$ Aerodynamic resistance to wet canopy evaporation $\left(\mathrm{sm}^{-1}\right)$

$r_{s}^{w c} \quad$ Surface resistance to wet canopy evaporation $\left(\mathrm{sm}^{-1}\right)$

$r_{a}^{t} \quad$ Aerodynamic resistance to wet canopy transpiration $\left(\mathrm{sm}^{-1}\right)$

$r_{s}^{t} \quad$ Surface resistance to wet canopy transpiration $\left(\mathrm{sm}^{-1}\right)$

$r_{s}^{s} \quad$ Surface resistances to soil evaporation $\left(\mathrm{sm}^{-1}\right)$

$r_{a}^{s} \quad$ Aerodynamic resistance to soil evaporation $\left(\mathrm{sm}^{-1}\right)$

$T_{a} \quad$ Air temperature $\left({ }^{\circ} \mathrm{C}\right.$ or $\left.\mathrm{K}\right)$

$\mathrm{gl} l_{\mathrm{sh}} \quad$ Leaf conductance to sensible heat flux $\left(\mathrm{ms}^{-1}\right)$

$\mathrm{gl}_{e w} \quad$ Leaf conductance to evaporated water $\left(\mathrm{ms}^{-1}\right)$

$g_{b l} \quad$ Leaf-scale boundary layer conductance $\left(\mathrm{ms}^{-1}\right)$

$G_{s}^{b} \quad$ Canopy-boundary-layer conductance $\left(\mathrm{ms}^{-1}\right)$

$G_{s}^{c u} \quad$ Cuticular conductance $\left(\mathrm{ms}^{-1}\right)$

continuous measurements of energy water and carbon fluxes in the context of the Large-Scale Biosphere Atmosphere (LBA) program (Araujo et al., 2002), these measurements are temporally limited and represent point-scale information only. Remote sensing driven models are presented as an alternative feasible means to overcome this issue and provide spatially distributed ET information at regional and global scale (Mu et al., 2011; Fisher et al., 2008; Miralles et al., 2011).

Remote sensing driven models generally require three categories of inputs: land surface variables, surface radiation and surface meteorology inputs. At regional and global scale, land surface variables could be obtained from MODIS sensor while surface radiation/meteorology inputs are commonly derived from reanalysis models. Uncertainty from $g_{s}^{c u} \quad$ Leaf cuticular per unit of LAI $\left(\mathrm{ms}^{-1}\right)$

$G_{s}^{s t} \quad$ Stomatal conductance $\left(\mathrm{ms}^{-1}\right)$

$C_{L} \quad$ Mean potential stomatal conductance $\left(\mathrm{ms}^{-1}\right)$

$m\left(T_{\min }\right) \quad$ Multiplier to limit $C_{L}$ by $T_{\min }(-)$

$m(V P D) \quad$ Multiplier to limit $C_{L}$ by VPD (-)

$T_{\text {minclose }} T_{\text {minopen }}$ Lower and upper threshold for $\mathrm{T}_{\min }$

$V P \mathrm{D}_{\text {close }}, V P \mathrm{D}_{\text {open }}$ Lower and upper threshold for VPD

$r b l_{\max }, r b l_{\min }$ Maximum and minimum values of $r_{s}^{s}$ (adjusted to air and pressure values) $\left(\mathrm{sm}^{-1}\right)$

$\mathrm{P} \quad$ Pressure $(\mathrm{Pa})$

$\alpha \quad$ Albedo (-)

$S R_{\text {in }}, L R_{\text {in }}$ Incoming shortwave and longwave radiation $\left(\mathrm{W} / \mathrm{m}^{2}\right)$

$\varepsilon_{a} \quad$ Air emissivity (-)

$\varepsilon_{s} \quad$ Soil emissivity (-)

$\varepsilon \quad$ Surface emissivity (-)

$\sigma \quad$ Stephan Boltzmann constant $\left(\mathrm{Wm}^{-2} \mathrm{~K}^{-4}\right)$

$T_{a n n} \quad$ Annual Temperature ( $\left.{ }^{\circ} \mathrm{C}\right)$

$W_{s} \quad$ Wind speed $\left(\mathrm{m} \cdot \mathrm{s}^{-1}\right)$

$u * \quad$ Friction velocity $\left(\mathrm{m} \cdot \mathrm{s}^{-1}\right)$

$\mathrm{z} \quad$ Height above the surface $(\mathrm{m})\left(\mathrm{T}_{\mathrm{a}}, \mathrm{W}_{\mathrm{s}}\right)$ measurement)

$\mathrm{d}_{0} \quad$ Zero plane displacement height (m)

$\mathrm{L} \quad$ Monin-Obukhov Length (m)

$\theta_{a}, \theta_{0} \quad$ Air and land surface potential temperature (K)

$\mathrm{k} \quad$ Von Karman's constant (0.41)

$g \quad$ Acceleration due to gravity $\left(\mathrm{ms}^{-2}\right)$

$\theta_{v} \quad$ Virtual potential air temperature (K)

$l \quad$ Length scale of leafs over viscous boundary layers occur (0.027)

$\Lambda \quad$ Evaporative fraction (-)

$\Lambda_{r} \quad$ Relative evaporative fraction (-)

$H_{w e t}, H_{d r y}$ Sensible heat at wet and dry limits $\left(\mathrm{W} / \mathrm{m}^{2}\right)$

$\lambda \mathrm{E}_{\text {wet }} \quad$ Latent heat flux at wet limit $\left(\mathrm{W} / \mathrm{m}^{2}\right)$

$f_{A W} \quad$ Available water fraction (-)

$f_{P E T} \quad$ ET/PET (-)

$A W \quad$ Actual plant-available water $\left(\mathrm{m}^{3} / \mathrm{m}^{3}\right)$

AWC Available water capacity of the soil $\left(\mathrm{m}^{3} / \mathrm{m}^{3}\right)$

$T_{\text {sk }} \quad$ Skin temperature (K)

$L_{v} \quad$ Latent heat of vaporisation $\left(\mathrm{J} \cdot \mathrm{kg}^{-1}\right)$

$r_{a} \quad$ Aerodynamic resistance $\left(\mathrm{sm}^{-1}\right)$

$r_{s} \quad$ Stomatal resistance $\left(\mathrm{sm}^{-1}\right)$

$q_{\text {sat }} \quad$ Specific humidity at saturation $\left(\mathrm{kg} \cdot \mathrm{kg}^{-1}\right)$

$q \quad$ Specific humidity $\left(\mathrm{kg}^{\mathrm{kg}}{ }^{-1}\right)$

Root $_{\mathrm{sm}} \quad$ Root zone soil moisture $\left(\mathrm{m}^{3} / \mathrm{m}^{3}\right)$

Soil $_{\mathrm{sm}} \quad$ Surface soil moisture $\left(\mathrm{m}^{3} / \mathrm{m}^{3}\right)$

$r_{\text {smin }} \quad$ Minimum stomatal resistance $\left(\mathrm{sm}^{-1}\right)$

$h \quad$ Canopy height $(\mathrm{m})$

$\mathrm{Rn}_{24} \quad$ Daily net radiation $\left(\mathrm{W} / \mathrm{m}^{2}\right)$

$\mathrm{e}_{\mathrm{aTmax}} \quad$ Air vapour pressure obtained at $\mathrm{T}_{\max }(\mathrm{Pa})$

$\mathrm{w}_{\mathrm{wp}} \quad$ Soil moisture content wilting point $\left(\mathrm{m}^{3} / \mathrm{m}^{3}\right)$

$\mathrm{w}_{\mathrm{fc}} \quad$ Soil moisture content wilting point $\left(\mathrm{m}^{3} / \mathrm{m}^{3}\right)$

these coarser reanalysis data was proved to impact the quality of the derived ET and its potential biases (Badgley et al., 2015). In particular, how differences in these input datasets, in conjunction with model uncertainty, contribute to variability in ET estimates is still a matter of debate (Vinukollu et al., 2011).

In the present study, four different remote sensing based evapotranspiration models were considered for daily evapotranspiration retrieval in the Amazonian tropical forests. Models considered are: a daily adapatation of the Priestley-Taylor monthly evapotranspiration algorithm (PT-JPL) described in Fisher et al. (2008). PM-Mu which is a Penman-Monteith based model using the parametrizatoion presented in (Mu et al., 2011). Surface Energy Balance System (SEBS) (Su, 2002) 
which parametrizes the interaction atmosphere-surface as a one-source model) and a daily adaptation of the LSASAF evapotranspiration operative algorithm (Ghilain et al., 2011).

In order to account for the impact of uncertainty in coarse meteorological data two different scenarios are considered: in-situ meteorological forcing and reanalysis meteorological forcing. Remote sensing data are provided by the MODIS sensor and reanalysis data by three different reanalyses: MERRA-2, ERA-Interim and GLDAS-2. In-situ meteorological data and eddy covariance data are obtained from the LBA network. In particular, the main research objectives of the current study are: 1) validate and inter-compare the performance of the selected algorithms at daily scale considering in-situ and reanalysis meteorological forcing, 2) evaluate the main sources of uncertainties of the selected algorithms, 3) assess the impact of uncertainties in meteorological inputs on ET estimation by intercomparing ET spatial patterns driven by the three renalyses and the four models considered.

\section{Evapotranspiration algorithms}

\subsection{Priestley-Taylor jet propulsion laboratory (PT-JPL)}

In PT-JPL algorithm actual ET is derived by scaling the Priestley Taylor PET (Priestley and Taylor, 1972) considering different ecophysiological, atmospheric and soil constraints. $\lambda E$ is partitioned into $\lambda \mathrm{E}_{I}, \lambda \mathrm{E}_{c}$ and $\lambda \mathrm{E}_{s}$ which are given by Eqs. (1)-(3).

$\lambda \mathrm{E}_{I}=f_{w e t} \alpha_{p t} \frac{\Delta}{\Delta+\gamma} R_{n c}$

$\lambda \mathrm{E}_{c}=\left(1-f_{w e t}\right) f_{g} f_{T} f_{M} \alpha_{p t} \frac{\Delta}{\Delta+\gamma} R_{n c}$

$\lambda \mathrm{E}_{s}=\left(f_{\text {wet }}+f_{S M}\left(1-f_{\text {wet }}\right)\right) \alpha_{p t} \frac{\Delta}{\Delta+\gamma}\left(R_{n s}-G\right)$

where $f_{\text {wet }}$ is given by $R H^{4}, f_{\text {wet }}$ is assumed to be zero for RH values less than 0.7. $e_{a}$ and $e_{s}$ were obtained at midday conditions (i.e. at $T_{\max }$ conditions). Preliminary analysis showed that using $e_{a}$ at this time instead of daily $e_{a}$ improved the results. $\mathrm{f}_{S M}$ is calculated as $R H^{V P D / 1000}, f_{g}$ and $f_{M}$ are given by the following ratios $f_{A P A R} / f_{I P A R}, \mathrm{f}_{A P A R} / \mathrm{f}_{A P A R \max }$ respectively. $f_{A P A R}$ is given by 1.3632 SAVI -0.048 and $f_{I P A R}$ by NDVI0.05 . SAVI is calculated as $0.45 \mathrm{NDVI}+0.132$ as in Ershadi et al. as $\exp \left(-\left(\frac{T_{\max }}{=}=\mathrm{T}_{o p t}\right)^{2}\right)$. In Fisher et al. (2008), $T_{\text {qpopt }}$

was estimated as the air temperature of the annual peak of canopy activity. Nevertheless, due to in-situ data scarcity for the present study $T_{\text {opt }}$ was fixed at a constant value of $25^{\circ} \mathrm{C}$. This value has been applied previously for global evapotranspiration modelling across different types of biomes (Yuan et al., 2010; García et al., 2013). $R_{n}$ is partitioned into $R_{n s}$ and $R_{n c}$ which are calculated as $R_{n} \exp (-0.6 L A I)$ and $R_{n}-R_{n s}$ respectively. Although PT-JPL model (Fisher et al., 2008) was originally developed for monthly time scale, previous studies showed that it can also be applied successfully considering daily inputs (Yao et al., 2017; García et al., 2013). With this daily assumption, G was considered negligible in the present study.

\subsection{Penman-Monteith (PM-Mu)}

Mu et al. (2011) follows Penman-Monteith logic (Monteith, 1965). $\lambda E$ is partitioned into $\lambda \mathrm{E}_{I}, \lambda \mathrm{E}_{c}$ and $\lambda \mathrm{E}_{s}$ which are given by Eqs. (4)-(6).

$\left.\lambda \mathrm{E}_{I}=f_{\text {wet }} f_{c} \frac{\Delta\left(R_{n c}-G\right)+\rho c_{P} V P D / r_{a}^{w c}}{\left(\Delta+\gamma_{\frac{r}{r_{a}^{w c}}}^{w c}\right.}\right)$

$\lambda \mathrm{E}_{c}=\left(1-f_{w e t}\right) f_{c} \frac{\Delta\left(R_{n c}-G\right)+\rho c_{P} V P D / r_{a}^{t}}{\left(\Delta+\gamma \frac{r_{s}^{t}}{r_{a}^{t}}\right)}$ $\lambda \mathrm{E}_{\mathrm{s}}=\left(\mathrm{f}_{w e t}+\mathrm{RH}^{V P D / 200}\left(1-\mathrm{f}_{w e t}\right)\right) \frac{\Delta\left(\mathrm{R}_{n s}-\mathrm{G}\right)+\left(1-f_{c}\right) \rho c_{P} V P D / r_{a}^{s}}{\left(\Delta+\gamma_{\frac{s}{r_{a}^{s}}}^{s}\right.}$

$f_{\text {wet }}$ is the same as PT-JPL. For interception, $r_{a}^{w c}$ and $r_{s}^{w c}$ are obtained as a function of $T_{a}$, LAI and $g l_{s h}$ and $g l_{e w}$ respectively. For transpiration, $r_{a}^{t}$ is calculated as a function of $T_{a}$ and $g_{b l}$ (assumed equal to $g l_{s h}$ ). $r_{s}^{t}$ is a function of $G_{s}^{b}$ (assumed equal to $g l_{s h}$ ), $G_{s}^{c u}$ (derived from adjusting a constant $g_{s}^{c u}$ to actual air and pressure values) and $G_{s}^{s t}$ (derived from the product of $C_{L} m$ (Tmin) $m$ (VPD) adjusted to actual air and pressure values). $m$ (Tmin) and $m(V P D)$ multipliers limit $C_{L}$ considering $T_{\text {minclose }}$ and $V P D_{\text {close }}$ lower thresholds (inhibition of transpiration) and $T_{\text {minopen }}$ and $V P D_{\text {open }}$ upper thresholds (no inhibition of transpiration). For soil evaporation, $r_{a}^{s}$ and $r_{s}^{s}$ are a function of $T_{a}, \mathrm{P}, V P D, r b l_{\max }$ and $r b l_{\min }$. In addition, $f_{\text {wet }}$ and soil moisture constraint $\mathrm{RH}_{200}^{V P D}$ are also considered in the $\lambda \mathrm{E}_{\mathrm{s}}$ calculation. $g l_{s h}, g l_{e w}, C_{L}, r b l_{\max }, r b l_{\text {min }}, T_{\text {minclose }}, T_{\text {minclose }}$, $V P D_{\text {minclose }}$ and $V P D_{\text {minclose }}$ are biome constant values. They were extracted from $\mathrm{Mu}$ et al. (2011) considering Evergreen Broadleaf Forests

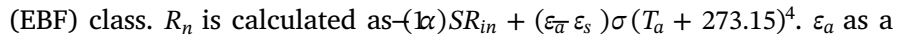
function of $T_{a}$ and $\varepsilon_{s}$ assumes a constant value of 0.97 (Mu et al., 2011). $R_{n}$ is partitioned into $R_{n s}$ and $R_{n c}$ considering $f_{c}$. $R_{n c}$ is calculated as $f_{c} R_{n}$ and $R_{n s}$ is calculatedlas $\left(f_{c}\right) R_{n}-G$. For the temperature

conditions of the Amazonian forests $\left(T_{a n n}>25^{\circ} \mathrm{C}\right.$ and daily temperature amplitude $<5{ }^{\circ} \mathrm{C}$ ) $\mathrm{Mu}$ et al. (2011) parametrization assumes a zero value for $G$. Daily ET is considered as the sum of daytime ET and nighttime ET. Both daytime and nighttime used the same algorithm with daytime and nighttime inputs respectively. For nighttime, transpiration is assumed negligible (Mu et al., 2011).

\subsection{Surface energy balance system (SEBS)}

In SEBS (Su, 2002), $\lambda E$ is obtained as a residual term of the surface energy balance. Accuracy in ET estimates is therefore set by accuracy in deriving $\mathrm{H}$. $\mathrm{H}$ is calculated by simultaneous solving of Eqs. (7)-(10).

$W_{s}=\frac{u_{*}}{k}\left[\ln \left(\frac{z-d_{0}}{z_{0 m}}\right)-\Psi_{m}\left(\frac{z-d_{0}}{L}\right)+\Psi_{m}\left(\frac{z_{0 m}}{L}\right)\right]$

$\theta_{0}-\theta_{a}=\frac{H}{k u * \rho c_{p}}\left[\ln \left(\frac{z-d_{0}}{z_{0 h}}\right)-\Psi_{h}\left(\frac{z-d_{0}}{L}\right)+\Psi_{h}\left(\frac{z_{0 h}}{L}\right)\right]$

$L=\frac{-\rho c_{p} u_{*}^{3} \theta_{v}}{k g H}$

$\ln \left(\frac{z_{o m}}{z_{o h}}\right)=\frac{52 \sqrt{u_{*} l}}{L A I}-0.69$

Inclusion of Eq. (10) was shown to provide a better parametrization for tall vegetation (Timmermans et al., 2013). $z_{0 m}$ was assumed a constant value of 2.5 (Brutsaert, 2005). $d_{0}$ was calculated as a function of tree height (Su et al.,2001). $\Psi_{m}$ and $\Psi_{h}$ are given by Brutsaert (1999). $\mathrm{H}$ estimates at this stage, are scaled between hypothetical dry and wet limits based on the relative evaporation (Eq. (11)). $\lambda \mathrm{E}$ can be finally derived by inverting $\Lambda$ (Eq. (12)). $\lambda \mathrm{E}_{\mathrm{wet}}$ is obtained as a residual value of the wet limiting case

$\Lambda_{r}=1-\frac{H-H_{w e t}}{H_{d r y}-H_{w e t}}$

$\Lambda=\frac{\Lambda_{r} \lambda \mathrm{E}_{\mathrm{wet}}}{R_{n}-G}=\frac{\lambda \mathrm{E}}{R_{n}-G}$

$R_{n}$ is given byl $(-\alpha) S R_{i n}+\varepsilon L R_{\text {in }}-\varepsilon \sigma L S T$ and $G$ is assumed as 0.34 $R_{n} \exp (-0.46 L A I)$. This new $G$ parametrization was shown to re-duced turbulent error estimation in comparison to $\mathrm{Su}$ (2002) formula-tion (Timmermans et al., 2013). SEBS was forced considering hourly input values at satellite time overpass. Constant evaporative fraction through the day was assumed to upscale instantaneous ET values to 
daily ET values (Gibson et al., 2011). High sensitivity to $\mathrm{Rn}_{24}$ in SEBS estimates is expected from this assumption. For daily inputs in $\Lambda$ calculation $\mathrm{G}$ was considered negligible. SEBS estimates on cloudy days (no LST data) was accomplished by considering $f_{A W}=f\left(f_{P E T}\right)$ relationship (Campbell and Norman, 1998). $f_{A W}$ is given by $A W / A W C$ ratio and $f_{P E T}$ by ET/PET ratio. AW for each day is calculated by decrementing AW of the previous day by the water loss of the day (daily ET amount). AWC is derived from soil texture values. Water available for transpiration was assumed to be supplied from a soil layer of 0-289 cm thickness according to root distribution in EBF forests (Van den Hurk et al., 2000). On clear days, AW pools are updated (i.e. $f_{A W}$ calculated from $f_{P E T}$ ). On cloudy days, $f_{P E T}$ can be calculated by inverting previous relationship. $E T$ can be therefore calculated as $f_{P E T} P E T$. PET is calculated as the maximum ET estimated value by SEBS (i.e. $\Lambda$ equal to 1 ). Further details of this gap filling technique are provided by Anderson et al. (2007). In order to facilitate notation for the rest of the paper, not gap filled SEBS model (clear days only) is named as SEBS and gap-filled model (clear and cloudy days) is named as SEBS-GF.

\subsection{Satellite application facility on Land surface analysis (LSASAF) algorithm}

LSASAF algorithm is based on a simplified SVAT scheme adapted to use remote sensed data and atmospheric model data as inputs (Ghilain et al., 2011). In original formulation, $\lambda E$ is calculated at a hourly scale and aggregated at a daily scale. In this study, in order to reduce the computational time associated model was forced directly considering daily inputs. In particular, daytime forcing was considered as nighttime model $\lambda E$ values were negligible. At this daytime scale $G$ was assumed to have a zero value. Preliminary analysis showed that calculating $G$ as in Ghilain et al. (2011) resulted in an overestimation of in-situ values (values is left). In addition, neglecting daytime $G$ is also assumed in PM$\mathrm{Mu}$ model for the study region conditions. In LSASAF algorithm, $\lambda E$ is calculated by iteratively solving the surface energy budget

$\left(R_{n}-\lambda \mathrm{E}-H=0\right)$. Components are given by Eqs. (13)-(15).

$R_{n}=(1-\alpha) S R_{i n}+\varepsilon\left(L R_{i n}-\sigma T_{s k}^{4}\right)$

$\lambda E=\frac{L_{v} \rho}{r_{a}+r_{s}}\left(q_{s a t}\left(T_{s k}\right)-q_{a}\left(T_{a}\right)\right)$

$H=\frac{\rho}{r_{a}}\left(c_{p}\left(T_{s k}-T_{a}\right)-g z\right)$

$r_{a}$ is calculated in a similar way to SEBS by considering the iterative solving of $u_{*} H$ and $L$ (Ghilain et al., 2011). $\Psi_{m}$ and $\Psi_{h}$ are given by Beljaars and Viterbo, (1994). $r_{s}$ is calculated as a function of LAI, $\mathrm{SR}_{\mathrm{in}}$, Root $_{\mathrm{sm}}$, Soil $_{\mathrm{sm}}, \mathrm{e}_{\mathrm{a}}, \mathrm{e}_{\mathrm{s}}$, and $r_{\text {smin }}$ following Jarvis (1976) approach adopted from van den Hurk et al. (2000). For the particular case of bare ground, a simplified formulation is used depending only on Soil $1_{s m}$ and $r_{\text {smin. }}$ (Ghilain et al., 2011). In this study, $\lambda E$ was calculated as $\mathbb{E}_{c} f_{c}+\lambda E_{s}$ $\left(1-f_{c}\right)$. EBF and bare soil classes (Ghilain et al., 2011) were se-lected in order to derive $\lambda E_{c}$ and $\lambda E_{s}$. For $z_{0 m}$ a value of 2.5 and 0.001

were considered for forests and bare soil (Brutsaert, 2005). $z_{0 h}$ was obtained as $0.1 z_{0 m}$ and $d_{0}$ as $\frac{2 h}{3}$ (Brutsaert, 2013). For bare soil a height of $0.01 \mathrm{~m}$ was considered.

\subsection{Evapotranspiration algorithms data requirements}

Evapotranspiration models considered in this study differ in the required input data and the parametrization of $\lambda E$ employed. In Table 1 are listed the required inputs and parameters. PT-JPL is the least-data demanding model. PM-Mu and LSASAF are the most complex and most demanding models as a result of aerodynamic and surface resistances explicit description. In PM-Mu, however no soil moisture is required. SEBS being less complex than PM-Mu/LSASAF is dependent to LST observations. Additional soil information is needed in order to provide estimates for cloudy days.

Differences in model $\lambda E$ parametrization arise from differences in the approach considered for ET estimation (scaling PET for PT-JPL, Penman-Monteih logic for PM-Mu, residual scheme for SEBS and SVAT scheme for LSASAF), differences in the evapotranspiration components modelled $\left(\lambda \mathrm{E}_{I}, \lambda \mathrm{E}_{c}\right.$ and $\lambda \mathrm{E}_{s}$ are considered for PT-JPL and PM-Mu, $\lambda \mathrm{E}_{c}$ and $\lambda \mathrm{E}_{S}$ are considered for LSASAF and $\lambda \mathrm{E}$ is considered for SEBS) and differences in explicit model parametrizations $\left(R_{n}, R_{n}\right.$ partition, $r_{a}$ and $r_{s}$ ).

\section{Data}

\subsection{In-situ data}

We used data from the LBA experiment available at ORNL Distributed Archive Active Centre (ftp://daac.ornl.gov/data/lba/carbon_dynamics/CD32_Brazil_Flux_Network/). A general description of the datasets can be found in Saleska et al. (2013). Only EBF stations (associated value of 2 in the International Geosphere-Biosphere Programme (IGBP) classification) were selected. In Table 2 and Fig. 1 characteristics and location of the sites are provided. In-situ station eddy-covariance fluxes were used to validate model ET estimates. Hourly $\lambda \mathrm{E}$ flux was converted to $\mathrm{mm}$ /hour and summed to daily values (mm/day). Daily values were excluded as missing data if less than 20 (out of 24) measurements were not available. Lack of energy balance closure was observed in the in-situ measurements (hourly energy balance closure for the stations was $78 \%$ (Fig. S1 supplementary material)). In order to account for this issue, two common non-closure techniques (Bowen Ratio (BR) Twine et al. (2000) and Energy Residual (ER) (Li et al., 2008)) were applied. Daily corrected evapotranspiration values were obtained by summing corrected hourly values $(\mathrm{mm} / \mathrm{h})$. Daily corrected values were filled as missing data if the ratio of corrected/uncorrected values was less than 0.5 or more than 2 as in Ershadi et al. (2014). In addition, in-situ surface radiation $\left(R_{n}, S R_{i n}, L R_{i n}\right)$ and surface meteorology inputs $\left(\mathrm{T}_{\mathrm{a}}, \mathrm{e}_{\mathrm{a}}, \mathrm{W}_{\mathrm{s}}, \mathrm{P}\right)$ were used for forcing evapotranspiration models. Hourly inputs were averaged over daily, daytime/nighttime time intervals in order to accommodate to models requirements. A minimum $\mathrm{SR}_{\text {in }}$ threshold of $10 \mathrm{~W} / \mathrm{m}^{2}$ was used for separating daytime and nighttime conditions.

Table 1

List of required data and parameters for evapotranspiration models as used in the present study. Static fields are indicated with an asterisk (*). Models were forced considering the temporal resolution indicated.

\begin{tabular}{|c|c|c|c|c|}
\hline Model & PT-JPL & $\mathrm{PM}-\mathrm{Mu}$ & SEBS & LSASAF \\
\hline Surface Radiation & $\mathrm{Rn}_{24}$ & $\mathrm{SR}_{\text {in }}$ & $\mathrm{SR}_{\text {in }}, \mathrm{LR}_{\mathrm{in}}, \mathrm{Rn}_{24}$ & $\mathrm{SR}_{\text {in }}, \mathrm{LR}_{\text {in }}$ \\
\hline Surface Meteorology & $\mathrm{T}_{\max }, \mathrm{e}_{\mathrm{aTmax}}$ & $\mathrm{T}_{\mathrm{a}}, \mathrm{T}_{\min }, \mathrm{T}_{\mathrm{ann}}, \mathrm{e}_{\mathrm{a}}, \mathrm{P}$ & $\mathrm{T}_{\mathrm{a}}, \mathrm{e}_{\mathrm{a}}, \mathrm{W}_{\mathrm{s}}, \mathrm{P}$ & $\mathrm{T}_{\mathrm{a}}, \mathrm{e}_{\mathrm{a}}, \mathrm{W}_{\mathrm{s}}, \mathrm{P}$ \\
\hline Land Surface Variables & NDVI, NDVI $I_{\max }$ & $\alpha$, LAI, $\mathrm{f}_{\mathrm{c}}{ }^{*}$ & LST, $\varepsilon^{*}, \alpha$, LAI, $h^{*}, f_{c}$ & $\varepsilon, \alpha, \mathrm{LAI}, \mathrm{h}, \mathrm{f}_{\mathrm{c}}$ \\
\hline Soil Variables & & & Soil texture & Root $_{\mathrm{sm}}$, Soil $_{\mathrm{sm}}$ \\
\hline Roughness Parameters* & & & $\mathrm{z}_{0 \mathrm{~m}}$ & $\mathrm{z}_{0 \mathrm{~m}}$ \\
\hline Biome parameters* & & $\mathrm{gl} \mathrm{s}_{\mathrm{sh}}, \mathrm{gl}_{\mathrm{ew}}, \mathrm{C}_{\mathrm{L}}, \mathrm{rbl}_{\text {max }}, \mathrm{rbl}_{\text {min }}, \mathrm{T}_{\text {minclose }}, \mathrm{T}_{\text {maxclose, }} \mathrm{VPD}_{\text {minclose }}, \mathrm{VPD}_{\text {maxclose }}$ & & $r_{\text {smin }}$ \\
\hline Temporal resolution & Daily & Daytime + Nighttime & Hourly + Daily upscaling & Daytime \\
\hline
\end{tabular}


Table 2

Description of the LBA tower sites used.

\begin{tabular}{|c|c|c|c|c|c|c|}
\hline Site name & Lat $\left({ }^{\circ}\right)$ & Lon $\left({ }^{\circ}\right)$ & $\begin{array}{l}\text { Tower } \\
\text { height (m) }\end{array}$ & $\begin{array}{l}\text { Canopy } \\
\text { height (m) }\end{array}$ & Data availability & Reference \\
\hline Manaus (K34) & -2.61 & -60.21 & 50 & 35 & $06-1999$ to $09-2006$ & Araujo et al. (2002) \\
\hline Santarem(K67) & -2.86 & -54.96 & 63 & 35 & $01-2002$ to $01-2006$ & Hutyra et al. (2007) \\
\hline Santarem (K83) & -3.02 & -54.98 & 64 & 35 & $06-2000$ to $12-2004$ & Goulden et al. (2004) \\
\hline Caxiuana (CAX) & -1.75 & -51.45 & 51.5 & 38 & $01-1999$ to $06-2003$ & Carswell et al. (2002) \\
\hline Reserva Jaru(RJA) & -10.08 & -61.93 & 60 & 30 & $03-1999$ to $10-2002$ & von Randow et al. (2004) \\
\hline
\end{tabular}

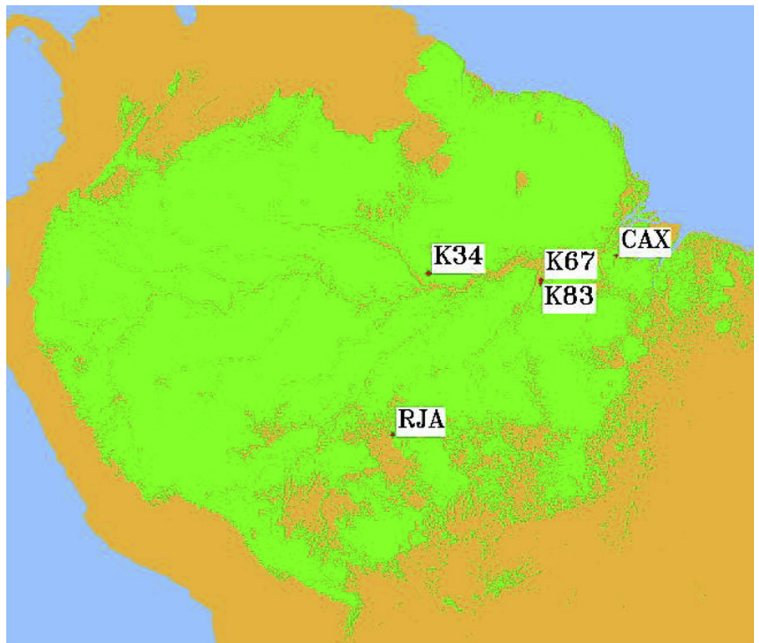

Fig. 1. Map of the Amazonian tropical forests indicating in-situ stations. In green the tropical forests region is delineated (For interpretation of the refer-ences to colour in this figure legend, the reader is referred to the web version of this article).

\subsection{Reanalysis data}

Meteorological data at a coarser resolution were obtained by three different reanalyses: MERRA-2 (Bosilovich et al., 2015), ERA-Interim (Dee et al., 2011) and GLDAS-2 (Rodell et al., 2004). MERRA-2 provides data at an hourly scale with a $0.5^{\circ} \times 0.65^{\circ}$ spatial resolution while ERAINTERIM and GLDAS-2 provide data at a three hourly scale with a spatial resolution of $0.75^{\circ} \times 0.75^{\circ}$ and $0.25^{\circ} \times 0.25^{\circ}$ respectively. Surface radiation $\left(\mathrm{Rn}_{24}, \mathrm{SR}_{\mathrm{in}}, \mathrm{LR}_{\mathrm{in}}\right)$ and surface meteorology inputs $\left(\mathrm{T}_{\mathrm{a}}\right.$, $\mathrm{q}, \mathrm{T}_{\mathrm{d}}, \mathrm{W}_{\mathrm{s}}, \mathrm{P}$ ) were directly provided by the reanalyses. $\mathrm{e}_{\mathrm{a}}$ was retrieved from $\mathrm{q}$ fields (MERRA-2 and GLDAS-2) or from $\mathrm{T}_{\mathrm{d}}$ fields (ERA-INTERIM). Root ${ }_{\mathrm{sm}}$ (ERA-Interim and GLDAS-2) was derived by averaging the four-layered reanalysis soil water content taking into account a modulating soil temperature function, the root distribution and fixed values of $\mathrm{w}_{\mathrm{wp}}\left(0.171 \mathrm{~m}^{3} / \mathrm{m}^{3}\right)$ and $\mathrm{w}_{\mathrm{fc}}\left(0.323 \mathrm{~m}^{3} / \mathrm{m}^{3}\right.$ ) (van den Hurk et al., 2000). Soil $1_{\mathrm{sm}}$ is computed in a similar approach but considering only the first soil layer. Root ${ }_{\mathrm{sm}}$ and Soil $l_{\mathrm{sm}}$ (MERRA-2) were computed by inverting root-zone and soil wetness derived from MERRA-Land (Reichle et al., 2011) considering previous fixed $\mathrm{w}_{\mathrm{wp}}$ and $\mathrm{w}_{\mathrm{fc}}$ values. Hourly and three hourly forcing inputs were averaged in order to obtain daily and daytime/nighttime values. Same in-situ $\mathrm{SR}_{\text {in }}$ threshold was considered for daytime and nighttime partition. For SEBS model, inputs at satellite time overpass were derived by linear interpolation between closest time acquisitions. For SEBS-GF, gridded soil properties $\left(\mathrm{w}_{\mathrm{wp}}\right.$ and $\mathrm{w}_{\mathrm{fc}}$ ) were obtained from Harmonized World Soil Database (HWSD)(FAO, 2012). They were indexed according to texture class (Anderson et al., 2007). Forcing inputs were spatially interpolated, considering a Gaussian interpolation between nearest neighbours, to a $1 \mathrm{~km}$ scale for validation purposes and at $5 \mathrm{~km}$ for regional scale implementation. In order to facilitate notation for the rest of the paper, MERRA, ERA and GLDAS are used as an abbreviation of MERRA-2, ERA-Interim, and GLDAS-2.

\subsection{Satellite data}

Land surface variables were derived from MODIS remote sensing data. $h$ was derived from Simard et al. (2011), global canopy height product. $f_{c}$ was derived from Broxton et al. (2014) in which vegetation fraction cover was derived from a MODIS multi-temporal analysis. $\varepsilon$ was calculated by weighting $\varepsilon_{v}$ and $\varepsilon_{s}$ by $f_{c}$ as in Sobrino et al. (2008). MODIS LST was derived from the split-window algorithm presented in Gomis-Cebolla et al. (2018). $\alpha$ and NDVI were obtained from MultiAngle-Implementation-Atmospheric-Correction (MAIAC) suite products (dataportal.nccs.nasa.gov). In order to avoid the lack of data due to continuous cloud coverage of the region monthly $\alpha$ and NDVI values were used to force the models. Missing monthly data was filled with the monthly climatological mean for the period 2000-2016. LAI was derived from NDVI as in Fisher et al. (2008). For remote sensing data, same spatial resampling as reanalysis input data was considered. For regional scale implementation, tropical forests were delineated con-sidering a vegetation mask derived from MCD12C1 product. Pixels flagged as EBF were intersected with a geographical vector covering the political regions of Amazonia

\section{Validation strategy}

\subsection{Algorithms validation}

Model performance was validated under two scenarios. In scenario I, models were forced using radiation and meteorology inputs from insitu stations, land surface variables from remote sensing data and Root $_{\mathrm{sm}}$ and Soil $l_{\mathrm{sm}}$ (LSASAF) from MERRA reanalysis due to the lack of stations soil moisture measurements. For scenario II, radiation, meteorology and with soil moisture inputs were retrieved from reanalysis (MERRA, ERA or GLDAS). Gridded soil properties (SEBS-GF) were derived from HWSD database and land surface variables were derived from remote sensing data. For each scenario, ET models estimates were validated using in-situ ET observations. In scenario $I$, due to $\mathrm{SR}_{\text {in }}$ data scarcity, LSASAF could be only run for K34, K83 and RJA stations and PM-Mu used $R_{n}$ for K67 station. SEBS also used station $R_{n}$ (due to the continuous lack of $\mathrm{SR}_{\mathrm{in}}$ and $\mathrm{LR}_{\mathrm{in}}$ measurements at LST time observations). The small number of available LST observations also limited SEBS model for CAX station. In scenario II, SEBS was not considered for validation (instead, SEBS-GF was used).

Metrics considered for validation include: bias, Root Mean Square (RMSE), correlation coefficient (R) and Taylor skill score (S) (Eq. (16)) (Taylor, 2001).

$S=4 \times \frac{1+R}{\left(\sigma_{\text {model }} / \sigma_{\text {obs }}+\sigma_{\text {obs }} / \sigma_{\text {model }}\right)^{2} \times\left(1+R_{0}\right)}$

where $R_{0}$ represents the maximum theoretical correlation $\left(R_{0}=1\right.$, in this study). $\sigma_{\text {model }}$ and $\sigma_{o b s}$ refers to the standard deviation of modelled and observed values respectively. $\mathrm{S}$ varies from zero to one. Higher $\mathrm{S}$ value indicating better performance. In addition, Taylor diagrams were used in order to compare models results in a comprehensive way. Three statistics are summarized in a Taylor diagram: standard deviation (STD) (displayed as the radial distance), correlation coefficient (displayed as the angle in the polar plot) and centered root mean square difference 
(CRMSD) (displayed as the distance to observation point which is given by $\mathrm{R}=1$, STD $=1$ and CRMSD $=0$ coordinates).

\subsection{Reanalysis quality assessment and sensitivity analysis}

Quality of reanalysis input data used in Scenario II was assessed by comparing reanalysis forcing inputs against in-situ forcing inputs. Same metrics used for model validation were considered. In addition, the effect of reanalysis input uncertainty on model output was evaluated using Global Sensitivity Analysis Sobol' method (Sobol, 2001; Saltelli et al., 2010). This method is based on ANOVA (analysis of variance) decomposition. Output model uncertainty (which results from propagating input variables uncertainty into the model) is decomposed into percentages that can be attributed to the independent contribution of input variables (Sobol first index) and interactions among inputs variables (Sobol second index). A total percentage can be computed gathering these two effects (Sobol total index). These percentages serve to identify the key input variables that drive model variance (i.e. the higher the percentage the higher the effect is). In order to perform this analysis, for each model mean monthly input values were perturbed using previous calculated input uncertainties (RMSE derived from quality assessment). This is the case for surface radiation and meteorology inputs. For Root sm $_{\mathrm{sm}}$ and Soil $1_{\mathrm{sm}}$ (no RMSE calculated) a $15 \%$ of variation was considered (obtained from the discrepancy amongst reanalysis soil moisture estimates). Land surface variables ( $\alpha$ and NDVI) were perturbed a $10 \%$ and LST was perturbed in a $\pm 3 \mathrm{~K}$ range. A minimum of 20,000 samples were considered in order to perform the analysis. For each month, the derived percentages will serve to identify the input variables that explains most of the model uncertainty.

\subsection{Spatial patterns comparison}

Models ET comparison at a regional scale (Amazonian tropical forests) was performed by assessing discrepancies in annual cumulative ET spatial patterns (year 2004) using difference maps and monthly zonal mean values. Spatial mean values were calculated considered only pixels from the vegetation mask described in Section 3.3. Four additional models (apart from models considered) were included for the comparison. In particular, GLEAM (Miralles et al., 2011; Martens et al., 2017), MERRA-Land (Reichle et al., 2011), ERA-INTERIM and GLDAS-2. GLEAM calculates ET via a PT approach considering a soil moisture stress computation and a Gash analytical model of rainfall interception loss (Miralles et al., 2011). MERRA-Land is an offline replay of MERRA with model-generated precipitation corrected using rain-gauge and with model parameter changes (Reichle et al., 2011). Surface fluxes in ERAINTERIM are based on land surface model TESSEL forced by atmospheric analysis and short range forecasts (van den Hurk et al., 2000). GLDAS consists of multiple off-line land surface models. For the study NOAH Land model was considered.

\section{Results}

\subsection{Forcing scenario $I$}

In Fig. 2 validation results considering all stations are presented using scatterplots. It is worth noting at this point that some discrepancy between metrics derived considering uncorrected and corrected ET estimates is expected. Models considered perform at $\mathrm{R}$ values ranging from 0.5 to approximately 0.9 . S values range from 0.7 to 0.9 and RMSE values lie between $0.55-1.25 \mathrm{~mm} /$ day. PT-JPL provides the highest $\mathrm{R}$ values range (0.65-0.88) in comparison to PM-Mu (0.56-0.74), SEBS (0.56-0.77), SEBS-GF (0.58-0.76) and LSASAF (0.53-0.69). In exception of LSASAF, best agreement between in-situ observations and models estimates is found when considering corrected ET measurements (i.e. an increase in R and $S$ values and a decrease in RMSE). In particular, maximum absolute deviations are obtained for LSASAF using these values. LSASAF generally tends to underestimate in-situ ET observations. For PT-JPL, PM-Mu, SEBS and SEBS-GF overestimation is generally observed for the uncorrected case. Bias values are decreased when considering ET corrected values. Best performance amongst models is obtained for PT-JPL (RMSE $=0.55 \mathrm{~mm} /$ day, $\mathrm{R}=0.88$ and $\mathrm{S}=0.91$ ) followed by SEBS (similar RMSE and $\mathrm{S}$ but lower R), SEBS-GF
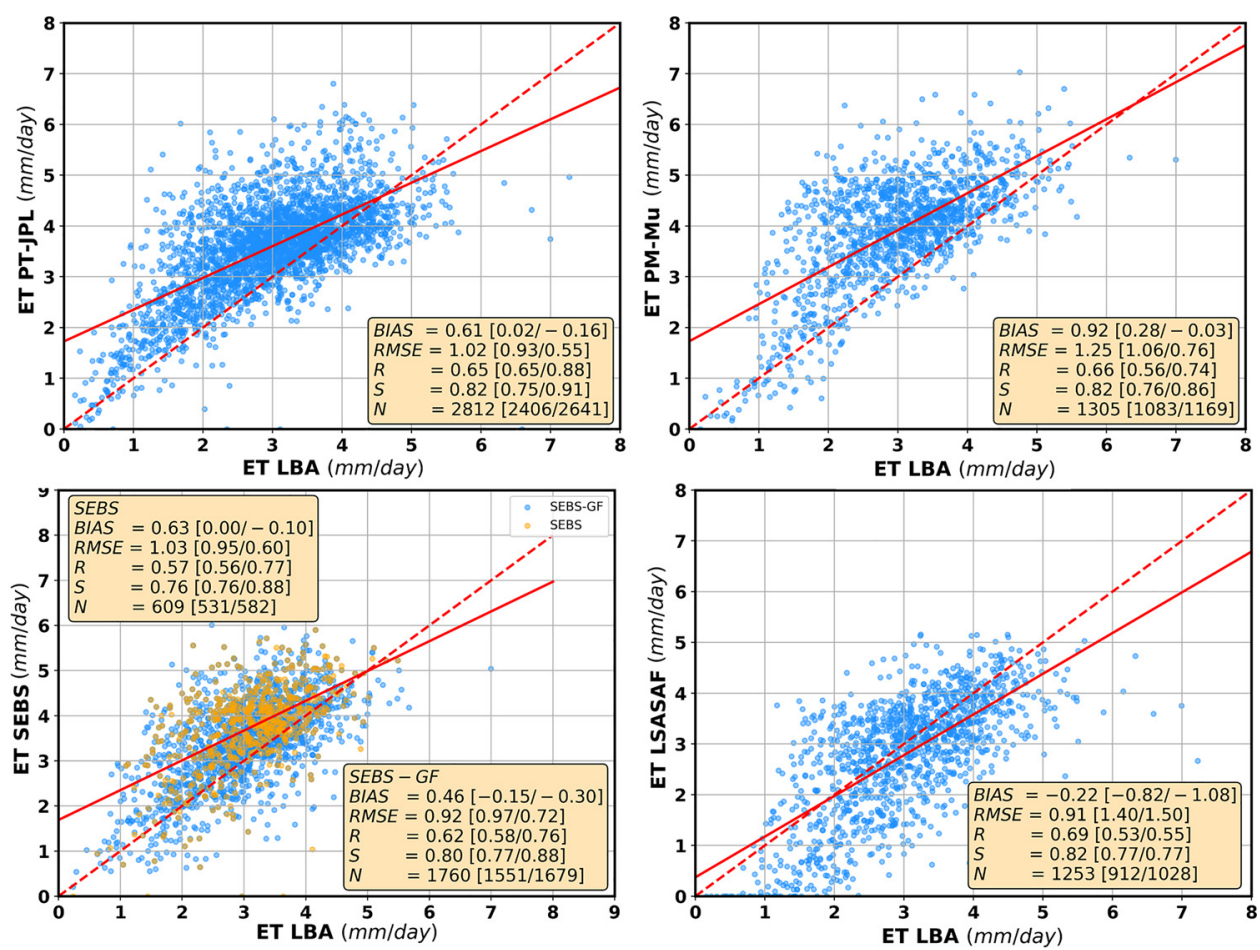

Fig. 2. Scatterplots of model ET estimate against in-situ ET uncorrected observations. Bias, RMSE, R, and S metrics were calculated considering observations from all the stations. Metrics derived considering corrected ET values (Bowen Ratio/Energy Residual) are presented between parenthesis. 
and PM-Mu. SEBS model especially suffers from the lack of input LST observations due to the continuous cloud cover of the region (minimum $\mathrm{N}$ value). On the contrary, PT-JPL being the least-data demanding is the less prone to suffer from the lack of input data issue (maximum $\mathrm{N}$ value). The gap-filling technique used is showed to alleviate in part this problem, nevertheless it is observed that SEBS-GF tends to underestimate SEBS values. Worst performance is obtained for LSASAF $($ RMSE $=1.50 \mathrm{~mm} /$ day, $\mathrm{R}=0.55$ and $\mathrm{S}=0.77$ )

Individual stations validations results were compared using Taylor Diagrams (Fig. 3). The bias metric is also included for comparison. Models are represented by colors and evapotranspiration corrections by shapes (triangle - ET (uncorrected ET values), square - BR (Bowen Ratio) and circle - ER (Energy Residual)). Models generally perform at $\mathrm{R}$ values ranging from 0.5 to 0.9 and CRMSD less than 1 . For CAX and RJA maximum $\mathrm{R}$ is obtained at 0.8. In addition, for RJA minimum $\mathrm{R}$ value is situated at 0.2 and CRMSD can be greater than 1 . Considering corrected ET values PT-JPL outperform the rest of the models (i.e. the blue square and the blue circle are closer to the observation point than the rest of the squares and circles respectively). For the uncorrected case there is no model that provides a superior performance for all the stations. In terms of the bias, it is observed that K34 and RJA contribute the most to the underestimation issue of LSASAF. For the rest of the models major deviations (positive biases) are obtained for RJA and CAX considering uncorrected ET values. A decrease is observed when considering the corrected case.

The temporal evolution of the models is compared considering time series of monthly mean values (Fig. 4). Values were calculated considering at least 15 points for each month. In-situ observations are also displayed. Variability in these measurements due to the energy balance closure issue is represented by the shadowed area. The lower, intermediate and upper limits indicate uncorrected, BR and ER correction ET observations respectively. A greater deviation is observed between uncorrected and corrected values than between corrections. Models generally followed in-situ ET temporal behavior with maximum values in September. LSASAF peaks in August, nevertheless it is worth noting that K67 and CAX were not able to be included (contrary to the rest of the models). Along the year, PT-JPL, SEBS and SEBS-GF always lie in the determined range of in-situ ET. PT-JPL and SEBS being closer to the corrected rank than SEBS-GF which tends to underestimate SEBS estimates. LSASAF clearly underestimates in-situ ET values. From May to

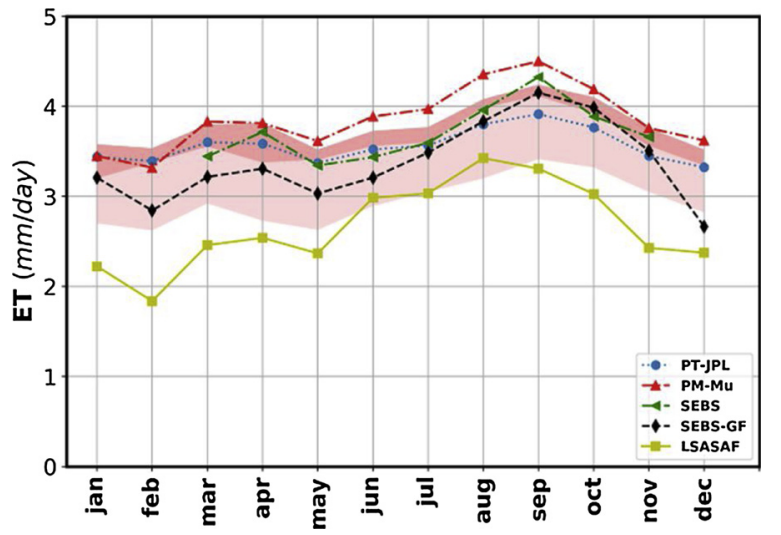

Fig. 4. Time series of ET model monthly mean values. In-situ ET observations are represented by the shadowed area (lower, intermediate and upper limit indicating uncorrected, BR and ER ET observations respectively).

October the deviation is reduced to the increase in ET estimates. In this same period overestimation is found for PM-Mu. Amongst the models considered the major coincidence is found for PT-JPL and SEBS. Nevertheless, due to the lack of LST input data a complete year of estimates is not reached for SEBS (July-October providing the maximum number of observations).

\subsection{Forcing scenario II}

\subsubsection{Reanalysis quality assessment and sensitivity analysis}

In Table 3 metrics (bias, RMSE and R) derived from the comparison of in-situ forcing inputs against reanalysis forcing inputs are resumed. Metrics were calculated with a number of available points ranging from 500 to 4000 depending on model and forcing variable considered. Generally, instantaneous values (at satellite time overpass) provide greater deviations from in-situ observations than averaged values (daytime, nighttime and daily). Main difference amongst radiation inputs is observed for the bias metric (similar RMSE and $\mathrm{R}$ values for the three reanalysis). MERRA tends to overestimate $\mathrm{Rn}_{24}, \mathrm{SR}_{\text {inday }}$ and $\mathrm{SR}_{\text {inhour }}$ while underestimating $L R_{\text {inday }}$ and $L R_{\text {inhour. }}$ Same behaviour is obtained for GLDAS although it tends to underestimate $\mathrm{SR}_{\text {inday }}$. ERA
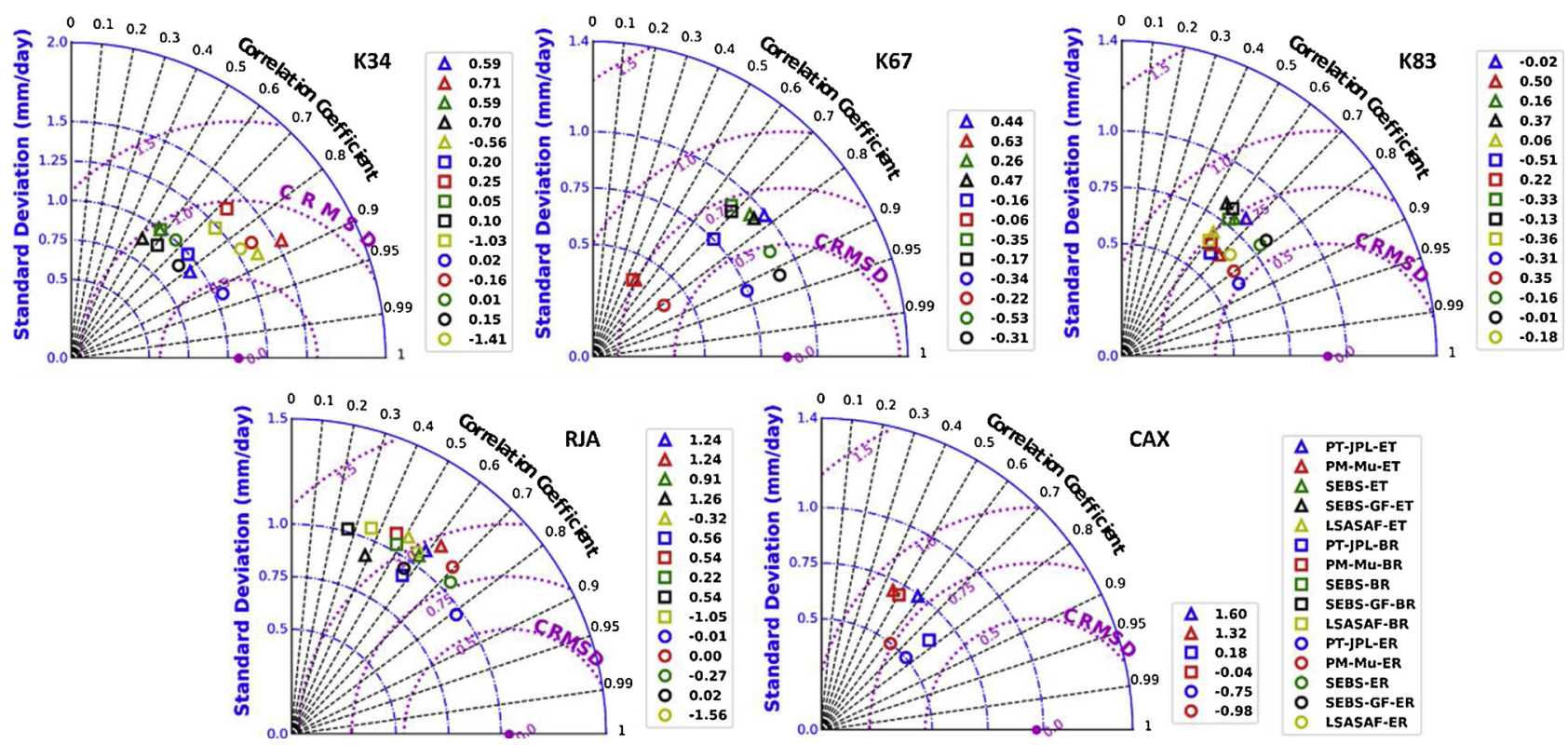

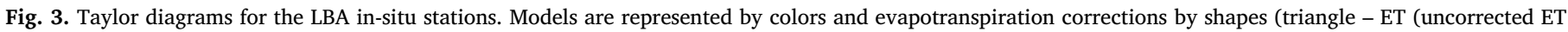
values), square - BR (Bowen Ratio) and circle - ER (Energy Residual)). 
Table 3

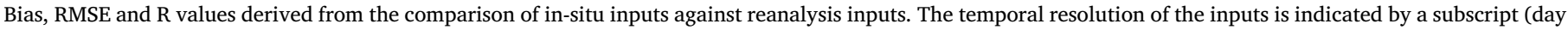
refers to daytime, night to nighttime and hour to hourly values at the time of satellite overpass).

\begin{tabular}{|c|c|c|c|c|c|c|c|c|c|}
\hline & \multicolumn{3}{|l|}{ MERRA } & \multicolumn{3}{|l|}{ ERA } & \multicolumn{3}{|l|}{ GLDAS } \\
\hline & BIAS & RMSE & $\mathrm{R}$ & BIAS & RMSE & $\mathrm{R}$ & BIAS & RMSE & $\mathrm{R}$ \\
\hline \multicolumn{10}{|c|}{ Radiation inputs $\left(\mathrm{W} / \mathrm{m}^{2}\right)$} \\
\hline $\mathrm{Rn}_{24}$ & 9.16 & 48.77 & 0.31 & -10.36 & 44.07 & 0.37 & 8.65 & 43.53 & 0.39 \\
\hline $\mathrm{SR}_{\text {inday }}$ & 10.70 & 124.17 & 0.26 & -37.54 & 113.43 & 0.37 & -28.56 & 109.08 & 0.37 \\
\hline $\mathrm{LR}_{\text {inday }}$ & -20.08 & 23.09 & 0.50 & -15.38 & 18.60 & 0.68 & -19.75 & 24.50 & 0.45 \\
\hline $\mathrm{SR}_{\text {inhour }}$ & 141.80 & 241.47 & 0.33 & 94.80 & 216.05 & 0.34 & 126.66 & 224.54 & 0.39 \\
\hline $\mathrm{LR}_{\text {inhour }}$ & -16.04 & 23.55 & 0.57 & 1.39 & 15.55 & 0.67 & -2.12 & 20.91 & 0.53 \\
\hline \multicolumn{10}{|c|}{ Temperature inputs (K) } \\
\hline $\mathrm{T}_{\text {aday }}$ & 0.38 & 1.95 & 0.48 & -1.24 & 2.07 & 0.61 & 0.31 & 1.99 & 0.58 \\
\hline $\mathrm{T}_{\text {anight }}$ & 0.75 & 1.85 & 0.34 & 0.10 & 1.31 & 0.62 & 0.60 & 1.73 & 0.48 \\
\hline $\mathrm{T}_{\text {ahour }}$ & 0.62 & 2.94 & 0.44 & 0.18 & 2.30 & 0.49 & 1.24 & 3.32 & 0.50 \\
\hline $\mathrm{T}_{\max }$ & 2.00 & 2.81 & 0.50 & 0.80 & 2.30 & 0.41 & 3.18 & 4.28 & 0.38 \\
\hline \multicolumn{10}{|c|}{ Humidity inputs $(\mathrm{Pa})$} \\
\hline $\mathrm{e}_{\mathrm{aTmax}}$ & -168.34 & 484.73 & 0.34 & 196.54 & 522.38 & 0.06 & 262.94 & 600.50 & 0.35 \\
\hline $\mathrm{e}_{\text {aday }}$ & -225.95 & 531.94 & 0.12 & -135.59 & 539.65 & 0.05 & -148.65 & 572.80 & 0.30 \\
\hline $\mathrm{e}_{\text {anight }}$ & 56.32 & 453.85 & 0.02 & -126.97 & 484.70 & 0.05 & -179.60 & 607.90 & 0.14 \\
\hline $\mathrm{e}_{\text {ahour }}$ & -327.23 & 542.32 & 0.29 & -249.13 & 533.60 & 0.21 & -524.65 & 787.30 & 0.17 \\
\hline \multicolumn{10}{|c|}{ Wind speed $(\mathrm{m} / \mathrm{s})$} \\
\hline $\mathrm{W}_{\text {sday }}$ & -1.29 & 1.38 & 0.53 & -0.44 & 0.68 & 0.60 & -0.96 & 1.06 & 0.51 \\
\hline $\mathrm{W}_{\text {shour }}$ & -1.92 & 2.18 & 0.34 & -0.09 & 0.93 & 0.56 & -0.77 & 1.19 & 0.55 \\
\hline
\end{tabular}

tends to overestimate instantaneous values while underestimating daytime and daily values. For temperature inputs (in exception of $\mathrm{T}_{\text {aday }}$ ) ERA provides the best agreement with in-situ observations amongst reanalysis. Overestimation is generally found for the three reanalysis (in exception of $\mathrm{T}_{\text {aday }}$ for ERA) with maximum deviations for $\mathrm{T}_{\max }$ and $\mathrm{T}_{\text {ahour. }}$ Contrary to temperature inputs (in exception of $\mathrm{e}_{\text {ahour }}$ ) ERA provides the worst performance for modelling humidity inputs (maximum $R$ value of 0.21 ). Maximum $R$ values are obtained for GLDAS however with also maximum RMSE values. In terms of bias, ERA and GLDAS overestimate $e_{a T m a x}$ while underestimate the rest of the inputs. MERRA only overestimates $e_{\text {anight }}$ however with a $R$ value of 0.02 . Wind speed inputs are underestimated for the three analyses. Best agreement is obtained for ERA (minimum RMSE and maximum $R$ values).
Results of sensitivity analysis are showed in Fig. 5. The mean RMSE value of the three reanalysis was considered for perturbing each input variable. It is observed that model output variability can be generally explained by input radiation variability. For PT-JPL $\mathrm{Rn}_{24}$ is able to completely explain model variability. For PM-Mu $\mathrm{SR}_{\text {inday }}$ (playing the major role) followed by $\mathrm{e}_{\text {aday }}$ and $\mathrm{T}_{\text {aday }}$ (especially from May to November) are the key variables driven model output. For SEBS, $\mathrm{W}_{\text {shour }}$, $\mathrm{SR}_{\text {inhour }}$ and LST contribute in a secondary way in comparison to $\mathrm{Rn}_{24}$. This input sensitivity is also expected for SEBS estimates on cloudy days (SEBS-GF) (PET is directly estimated from $\mathrm{Rn}_{24}$ ). For LSASAF, model output variability can be explained by $\mathrm{SR}_{\text {inday }}$ followed by Root $_{\text {smday }}$, $\mathrm{e}_{\text {aday }}$ and $\mathrm{T}_{\text {aday }}$. Taking into account the sensibility of the models to this variables, uncertainty in these inputs will be directly translated into
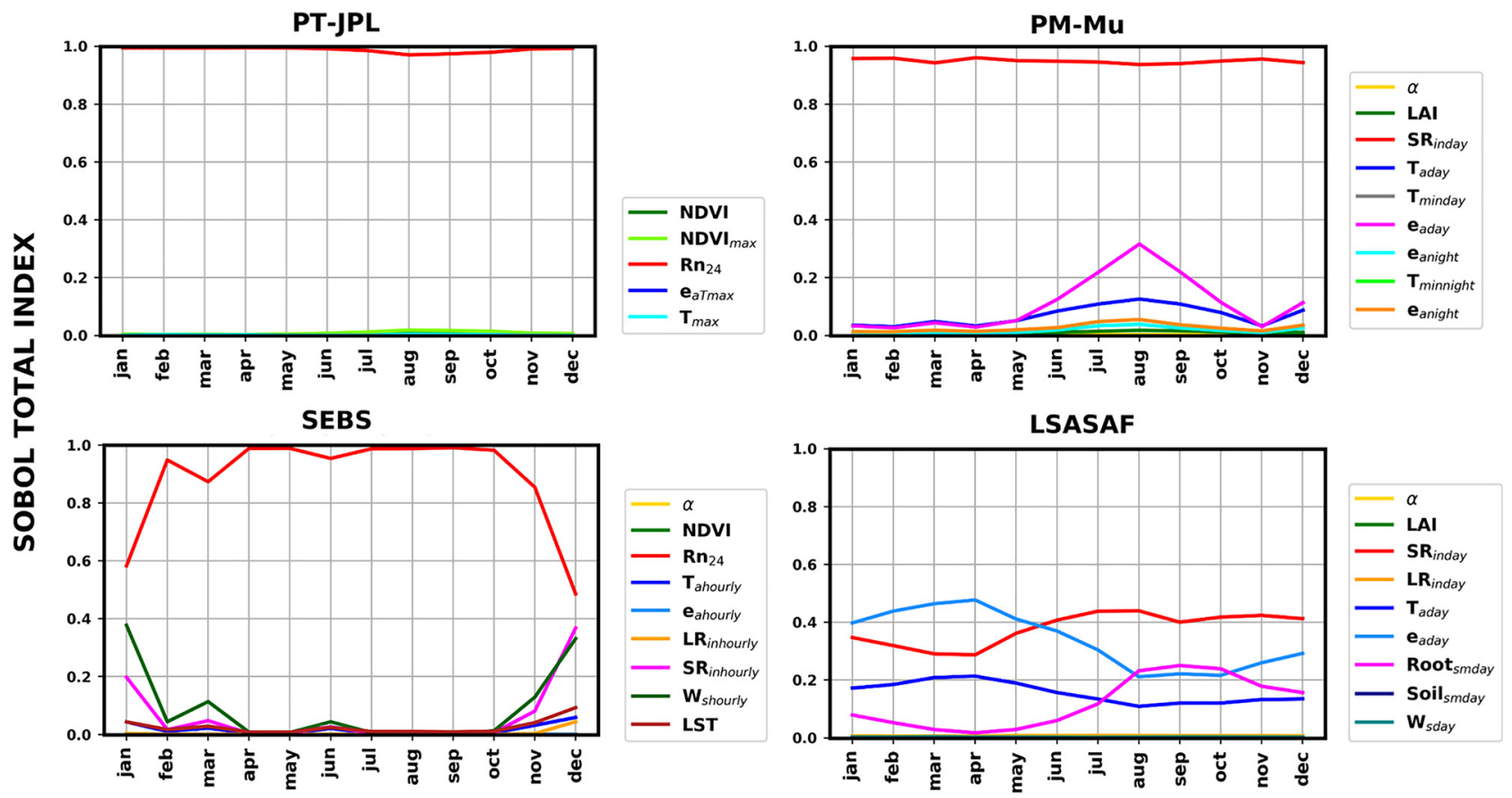

Fig. 5. Sobol sensitivity analysis for the models considered. Temporal resolution of model inputs is indicated by a subscript (day refers to daytime, night to nighttime and hour to hourly values at the time of satellite overpass). 
model uncertainty.

\subsubsection{Algorithm validation}

In Fig. 6 scenario II validation results are presented using scatterplots. A deterioration in model performance from Scenario I is observed ( $R$ and $S$ metrics have decreased while RMSE has increased). Taking into account reanalysis input quality this result was expected. $R$ metrics range from 0.2 to 0.3 . S metrics range from approximately 0.5 to approximately 0.7 and RMSE values lie in the range of $1.1-1.7 \mathrm{~mm} /$ day. It is worth noting here the coincidence between the models $R$ values range and the previous $R$ values range derived for the radiation inputs. In addition, there is an agreement between overestimation/underestimation for the models and the positive/negative bias calculated from the reanalysis inputs $\left(\mathrm{Rn}_{24}\right.$ and $\left.\mathrm{SR}_{\mathrm{in}}\right)$. For PT-JPL and SEBS-GF which uses $\mathrm{Rn}_{24}$ input, ERA forced results always tend to underestimate MERRA and GLDAS results (positive bias for MERRA/GLDAS and negative for ERA). Same conclusion is obtained considering $\mathrm{SR}_{\text {in }}$ and PM$\mathrm{Mu}$ and LSASAF. In terms of R, $\mathrm{S}$ and RMSE metrics, there is no particular combination (model + reanalysis) that clearly outperform the rest of the combinations (PM-Mu-ERA and LSASAF-MERRA however provide the best metrics but with little discrepancy from the rest)

Individual stations uncorrected validation results are showed in Fig. 7. The bias metric is also included for comparison. Taylor diagrams considering corrected ET observations are showed in supplementary material (Figs. S2, S3). Nevertheless, same conclusions can be obtained. Models are represented by shapes (triangle, square and circle) and reanalysis by colors. Models generally perform at $\mathrm{R}$ values ranging from -0.1 to 0.5 and CRMSD greater than 1 . On the contrary to scenario I,
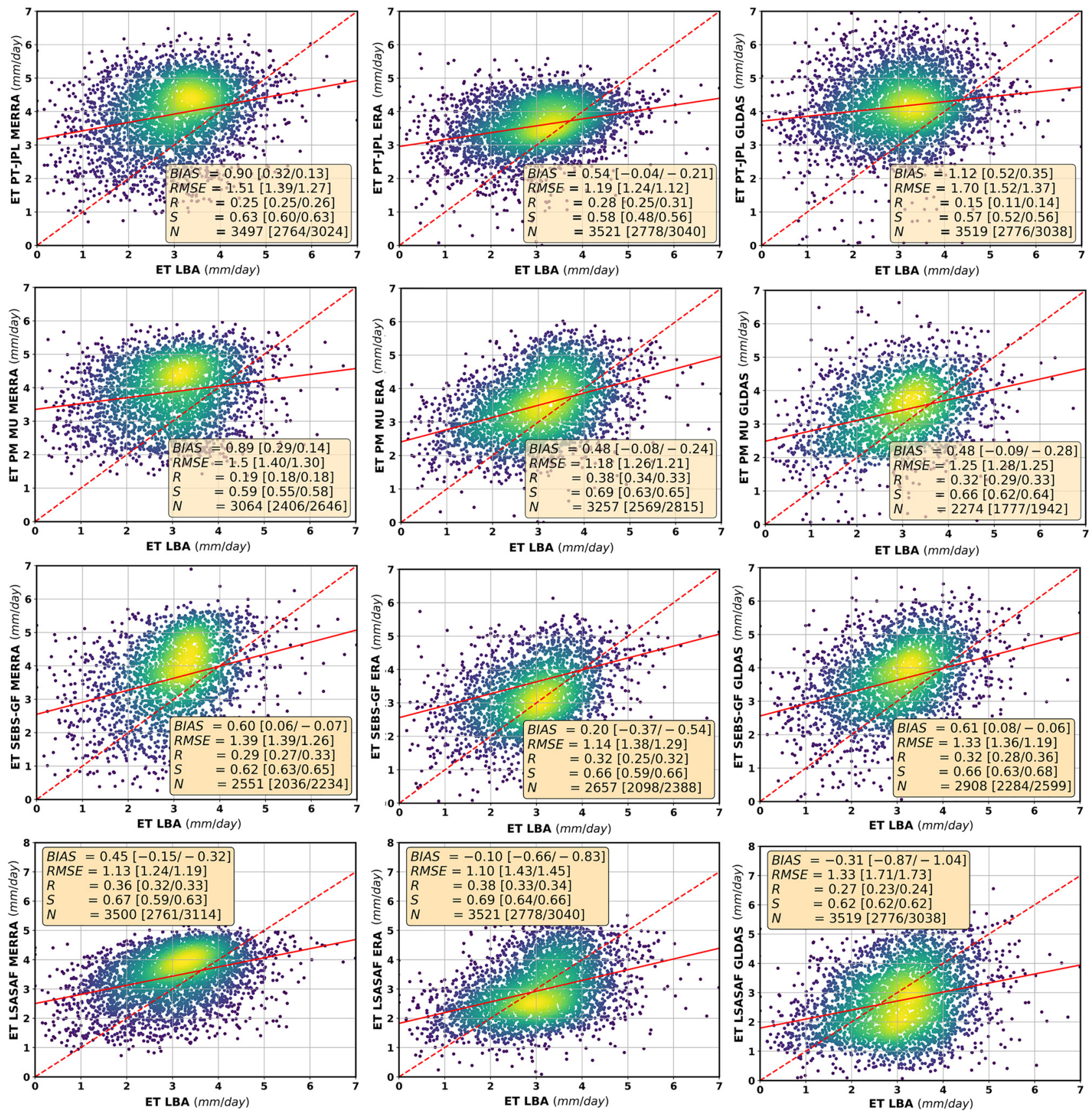

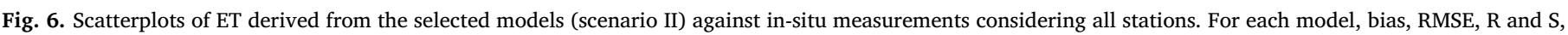

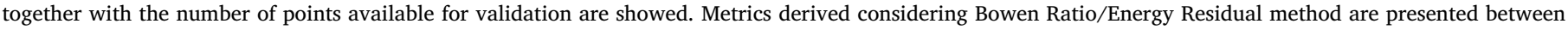
parenthesis. 

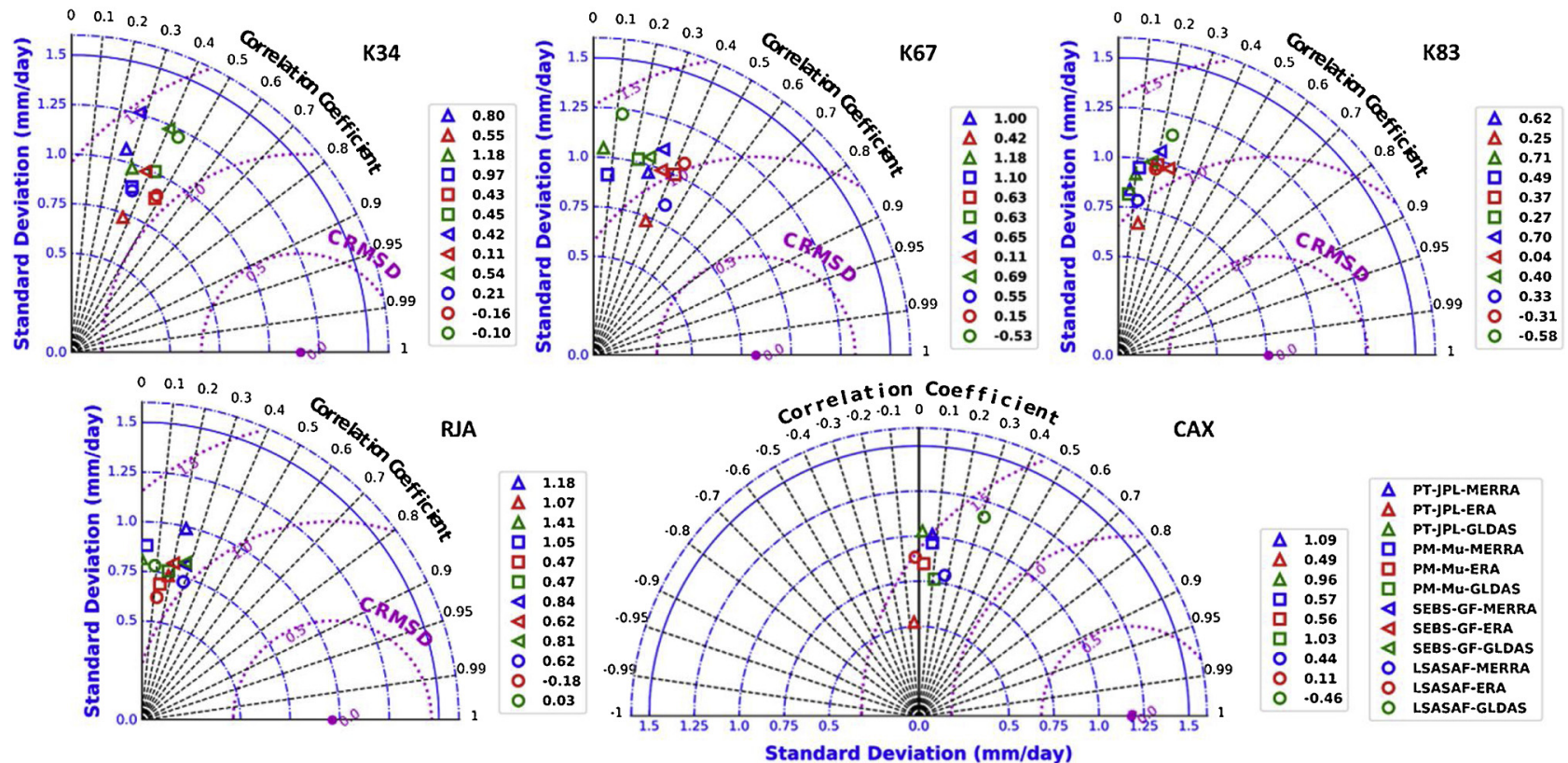

Fig. 7. Taylor diagrams for individual station considering reanalysis forcing.

there is no combination (model + reanalysis) that provides the maximum agreement for all the stations. Nevertheless, in general, PT-JPLERA and LSASAF-MERRA tend to provide the minimum CRMSD values. In the case of K34 station, this value is provided by PM-Mu-ERA and LSASAF-ERA. In terms of the bias metric, all the stations contribute with a positive bias (Fig. 7) to the overall overestimation in Fig. 6 (uncorrected ET values). Same applies for LSASAF-ERA and LSASAFGLDAS, overall underestimation values can be explained by the negative bias (or small positive bias) of the stations. Only in the particular case of SEBS-GF-ERA and LSASAF-GLDAS, RJA station contribute the most and the least to the overall bias.

In-situ forced and reanalysis forced ET estimates were compared considering the time series of monthly mean values (Fig. 8). In-situ ET observations were also included for comparison (same shadowed area as in Fig. 4). For PT-JPL model, MERRA and GLDAS tend overestimate in-situ forced estimates while ERA tend to underestimate these values. For MERRA and GLDAS this overestimation also results in an overestimation of in-situ observations for both uncorrected and corrected values. ERA is still within the range of ET observations values. For PM$\mathrm{Mu}$, MERRA provides the major coincidence with in-situ forced estimates. ERA and GLDAS on the contrary tend to underestimate these values. This fact however tends to alleviate PM-Mu overestimation issue and thus results in a better agreement with in-situ observations. For SEBS-GF scenario II estimates generally follow scenario I estimates. A positive deviation is found for MERRA and GLDAS. ERA provides the maximum (and negative) deviation. For LSASAF, maximum
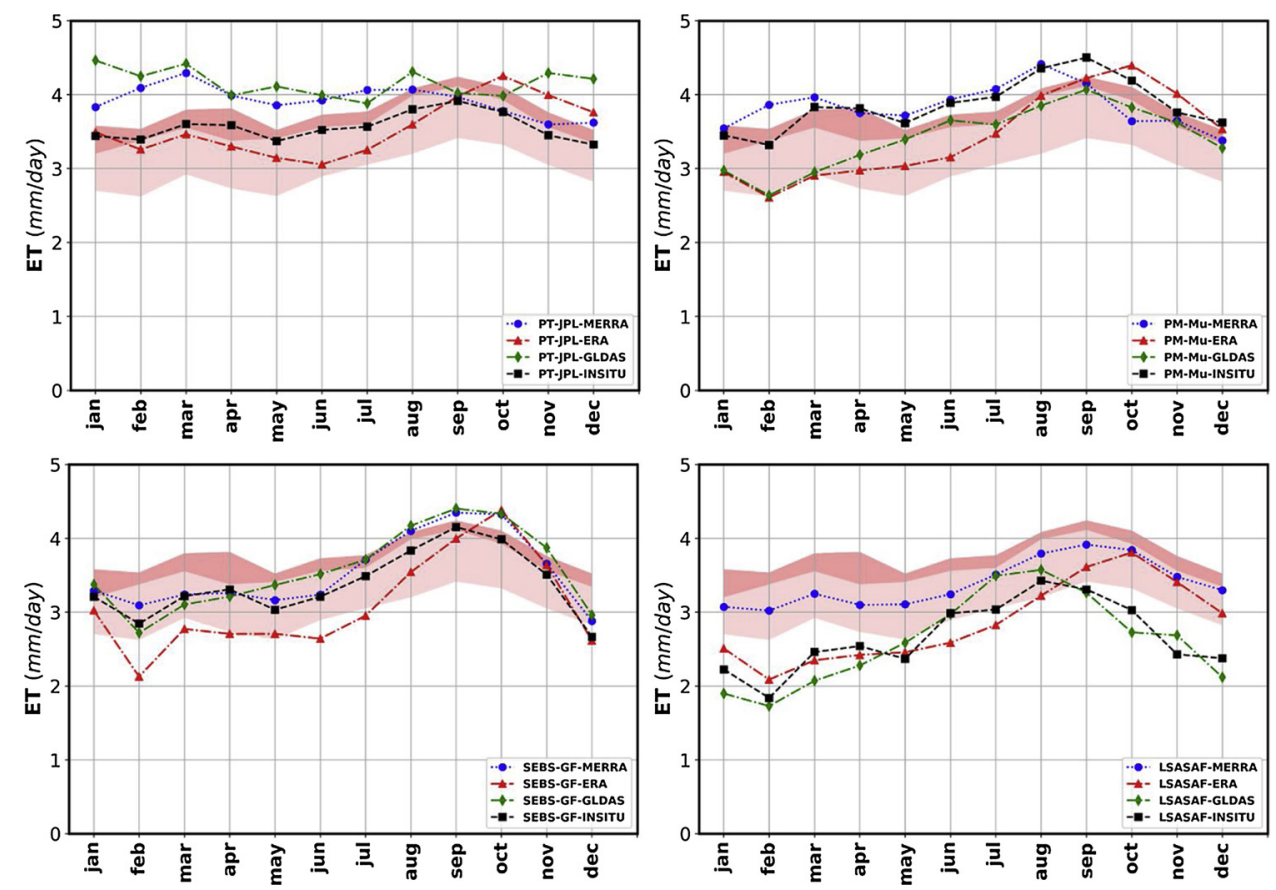

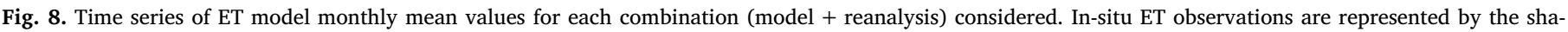
dowed area (lower, intermediate and upper limit indicating uncorrected, BR and ER ET observations respectively). 
discrepancy among scenarios is obtained for MERRA. This deviation results in a better agreement with in-situ observations. ERA and GLDAS tend to follow scenario I estimates, maximum difference between reanalysis is found from September to October. Analyzing results by reanalysis, a strong seasonal behavior (similar temporal pattern for all the models) is found for ERA in contrast to MERRA and GLDAS.

\subsubsection{Spatial patterns}

In Fig. 9 the difference maps used for the comparison of model spatial patterns are showed. The ensemble (mean value) of all the models was considered as truth data. From Fig. 9, it is observed that discrepancies amongst reanalysis can induce maximum absolute differences greater than $500 \mathrm{~mm} /$ year in annual cumulative ET values. Maximum negative deviations are obtained for LSASAF-ERA and LSASAF-GLDAS followed by LSASAF-MERRA and PM-Mu-ERA and PMMu-GLDAS. Maximum positive deviations are obtained for MERRA and GLDAS followed by PT-JPL-GLDAS and SEBS-GF-GLDAS. In addition, discrepancy amongst spatial patterns can be explained by differences in reanalysis inputs. In particular, it is observed that models driven by the same radiation input (PT-JPL/SEBS-GF for $\mathrm{Rn}_{24}$ and PM-Mu/LSASAF for $\mathrm{SR}_{\text {in }}$ ) tend to share similar spatial patterns (although some dis-crepancy may exist). This leads to the conclusion that differences in ET spatial patterns are generally explained by differences amongst re-analysis radiation inputs. In Fig. 10, difference maps of $R_{24}$ and $S_{\text {in }}$ are showed. Ensemble (mean value) of the three reanalysis was con-sidered as truth data. Comparing Figs. 10 and 11 it is observed ET spatial patterns generally reproduce input radiation spatial patterns. From the reference models considered (GLEAM, MERRA, ERA and
GLDAS) major deviations from the ensemble model are obtained for GLEAM and MERRA. In Fig. 11, the temporal evolution of the models is displayed using zonal mean values. Input net radiation is also displayed for comparison. Taking into account that growth and water use in tropical forests is radiation driven (Myneni et al., 2007; Wagner et al., 2017) the comparison with radiation evolution can serve to indicate model performance. Discrepancies amongst model temporal evolution is also driven by reanalysis differences. For each reanalysis, models follow the same temporal pattern although differing in ET absolute values. Models are able to reproduce the temporal evolution of net radiation. Major deviation is obtained for PT-JPL-GLDAS. In particular, ERA follows a stronger seasonal net radiation evolution in comparison to GLDAS and MERRA. Considering the comparison of model temporal evolution between the reference models and the four models considered, the agreement with GLDAS and ERA is greater than with GLEAM and MERRA. In GLDAS and ERA the increase in ET values is observed for the period of May-December (with a peak in September/ October) while for GLEAM and MERRA this behaviour is observed from January to September (with minimum values in September).

\section{Discussion}

\subsection{Forcing scenario $I$}

$\mathrm{R}_{\mathrm{n}}$ was shown to control the seasonal variation of $\lambda E$ over the tropical forests in Amazonia (Fisher et al., 2009; Rocha et al., 2009). The four models considered rely on radiation inputs for evapotranspiration estimation, hence their general agreement with in-situ observations

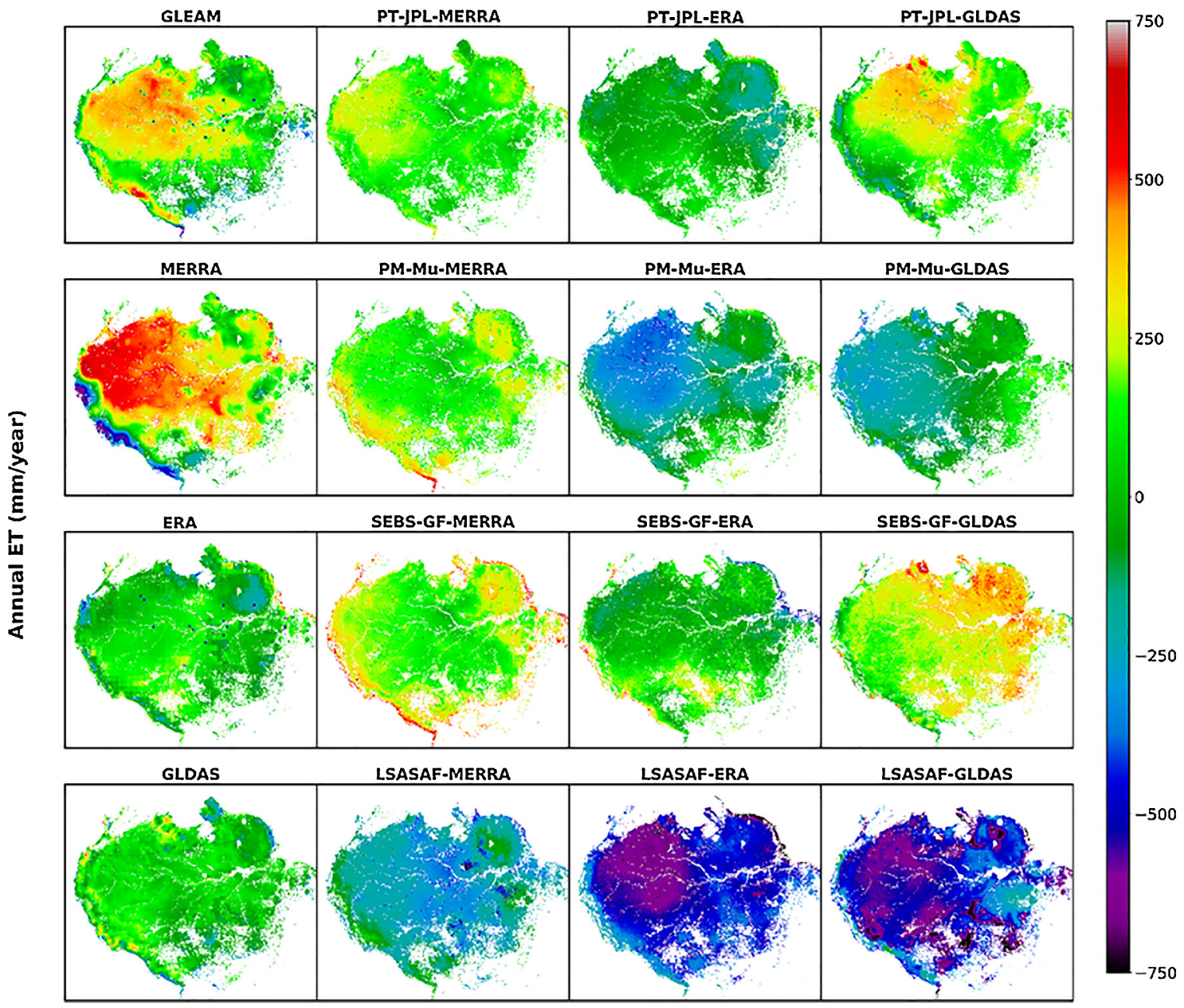

Fig. 9. Annual cumulative ET (year 2004) spatial patterns (deviation from the ensemble mean). 


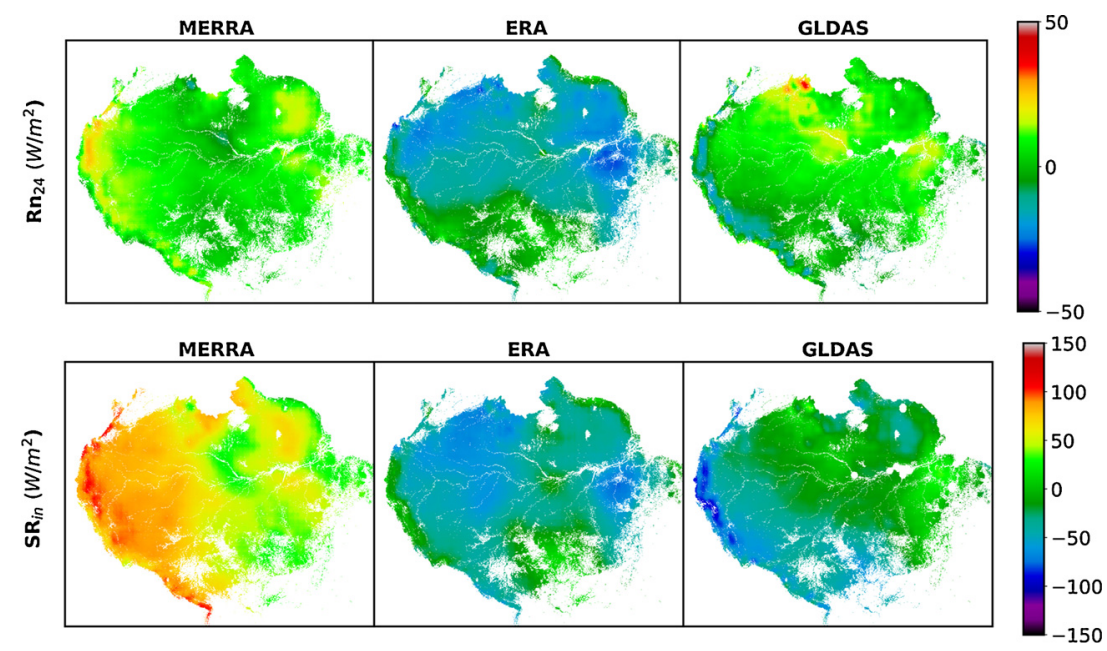

Fig. 10. Spatial patterns of annual mean $\mathrm{Rn}_{24}$ and $\mathrm{SR}_{\text {in }}$ (deviation from the ensemble mean).

(Fig. 2 and Fig. 4). Nevertheless, the best performance was obtained for PT-JPL (minimum RMSE and maximum $R$ values range) (Fig. 2). Same conclusion is derived for each individual station (minimum distance to the observation point, Fig. 3). These results could be attributed to the simplified approach used in estimating ET, which avoids the need of explicitly parametrizing the aerodynamic and surface resistances. As $\lambda E$ is mainly explained by $R_{n}$, the use of a more complex description (resistances) is not expected to contribute in a significant amount to $\lambda E$ explanation, instead additional noise is introduced by the use of additional parameters (Fisher et al., 2005). This is particular true for PM-Mu model. Considering the same $\lambda E$ partition as PT-JPL, the resistance formulation proposed does not result in an improved performance. These resistances are calculated using the biome-specific physiological parameters in Table 1 . The most arguably assumption about these values is that they do not change over space or time. For all the forests of the Amazon region same generic biome-specific properties are assumed, thus ignoring the high species diversity and the complex forest canopy structure. PM-Mu, however, succeeds in avoiding the need of soil moisture data, which for the region it is one of the most difficult parameter to model (Fisher et al., 2009). Main issue associated with PM$\mathrm{Mu}$ is that it tends to overestimate in-situ ET observations (Fig. 4). Maximum deviations are reached in months with maximum radiation. Validation of PM-Mu modelled net radiation against in-situ $R_{n}$ values providing an underestimation of approximately $20 \mathrm{~W} / \mathrm{m}^{2}$ for daytime $R_{n}$ (Table S1, supplementary material) suggested that this issue results from model itself (an underestimation of $R_{n}$ values results in an overestimation of ET values). This behaviour can be alleviated considering even lower $R_{n}$ values resulting from a lower $f_{c}$ value. It is worth noting here that same $f_{c}$ value $(0.98)$ derived from stations characterization (see references Table 2) was assumed for all the models. In MODIS
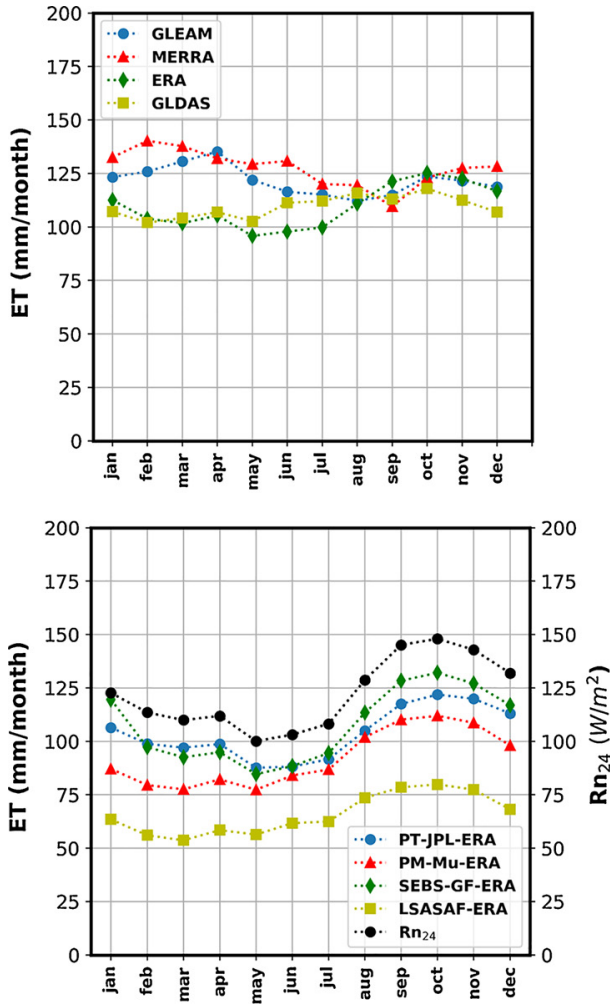
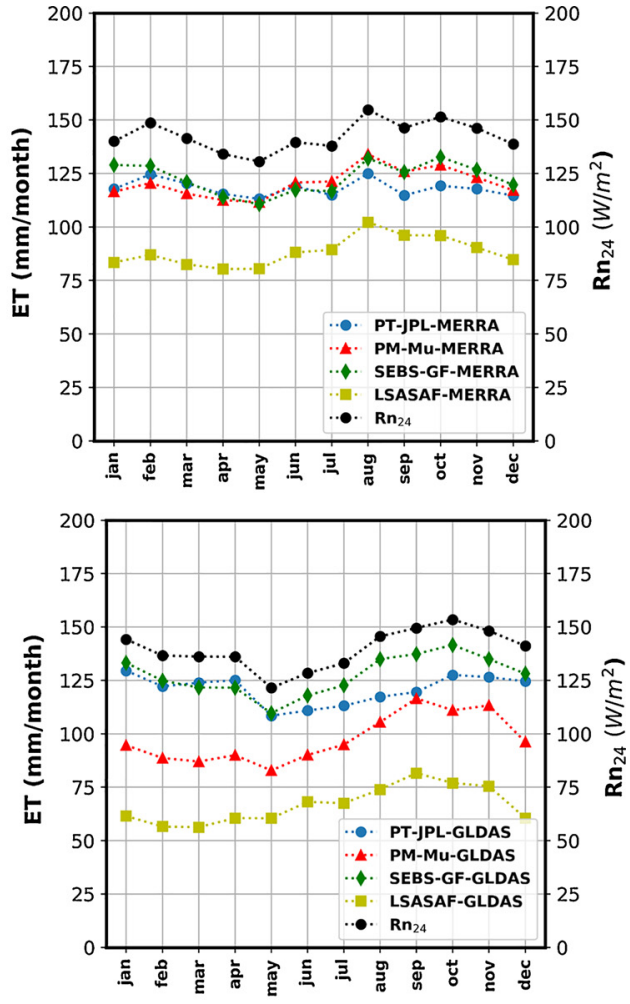

Fig. 11. Temporal evolution of zonal mean values for the Amazonian region. 
operative implementation however fapar is used as a surrogate of $f_{c}$. With this lower value $(0.85)$ this overestimation issue is somewhat alleviated (Figure S4 and Table S2, supplemetary material), nevertheless same conclusions from model comparison can still be derived. In this case altough a general agreement with in-situ observations is obtained input values differ from their optimum values (underestimation of $R_{n}$ and $\mathrm{f}_{\mathrm{c}}$ ). It is worth noting here that PM-Mu biophysical parameteres were calibrated globally, therefore some improvement could still be expected from local calibration.

SEBS model perform similar to PT-JPL, main discrepancy arises in R and $S$ metrics. This similar performance could be attributed that both models heavily rely on daily $\mathrm{R}_{\mathrm{n}}$ for ET estimation. In PT-JPL, PET (and therefore daily $R_{n}$ ) is scaled to ET values using biophysical constraints, for SEBS daily $R_{n}$ is scaled using a pre-calculated evaporative fraction. As this fraction is calculated at the satellite time overpass, the varia-bility introduced by using instantaneous values together with the as-sumption of constant value of evaporative fraction could help to explain the discrepancy for $\mathrm{R}$ and $\mathrm{S}$ metrics. In SEBS, the explicit para-metrization of surface resistance (and the problematic parametrization associated) is avoided by calculating $\lambda E$ as a residual term. Accuracy in the results is thus determined by the accuracy in calculating $r_{a}$ (and the derived $\mathrm{H}$ ). Van der Kwast et al. (2009) pointed out to LST errors as a

source of $r_{a}$ uncertainty. In particular, the split-window algorithm used in this study was demonstrated to provide more accurate LST estimates than current MODIS LST operative products (Gomis-Cebolla et al., 2018). In addition, possible deviations introduced by a deficient roughness and ground heat flux parametrization were addressed following Timmermans et al. (2013) indications. SEBS differ from the rest of the models in the fact that no $\lambda E$ partition is considered. Nevertheless, SEBS one-source approach can be assumed for the region $\left(\lambda E_{s}\right.$ can be neglected, and the LST observations are expected to reflect the effect of intercepted water on the leaves and canopy for $\lambda E_{I}$ ). Main limitation of SEBS model is the lack of ET estimates for cloudy days. In order to deal with this problem, ET was derived from the $f_{A W}$ in these days. This technique was shown to overcome this issue nevertheless it tended to underestimate SEBS values. This fact may result from the simplification used (transpiration results only from the contribution of soil moisture). Although this assumption is generally true for water limited regions it may not offer a complete description for energy limited regions (evapotranspiration is mainly determined by the incoming radiation rather than the available water). In addition, this gapfilling technique entails one additional aspect, the alteration in the ET estimates distribution. Due to the continuous cloud cover of the study region, $f_{A W}$ ET estimates contribute more to the total distribution than SEBS estimates (i.e. from approximately 1600-1700 SEBS-GF estimates, only 500-600 are from SEBS).

LSASAF provides the worst performance amongst the models considered. ET estimates were clearly underestimated. In LSASAF, an explicit parametrization of $r_{s}$ and $r_{a}$ is used in order to estimate $\lambda E . r_{s}$ is calculated by upscaling $r_{\text {smin }}$ using Jarvis functions. A constant value of $r_{\text {smin }}$ is assumed for all the forests of the Amazonia. Apart from this issue, the soil moisture is considered in this calculation. The proble-matic description of this input together with the spatial mismatch be-tween insitu point station and reanalysis data negatively affect model performance. In addition, as in SEBS, there is a dependency on

roughness parameters for $r_{a}$ calculation. Therefore, uncertainty in this parametrization could also affect model performance. Nevertheless, the main reason behind the underestimation of LSASAF model is the not inclusion of a $\lambda E_{I}$ term in the $\lambda E$ partition. In order to test this hypothesis, $\lambda E_{I}$ was calculated assuming $r_{s}$ equal to 0 (as in open waters) and using same vegetation roughness lengths driving $r_{a}$. $\lambda E$ components were weighted as in PM-Mu. Results indicated (Fig. S5 and Table S3, Supplementary material) that the inclusion of this new term help to overcome the underestimation issue. Although some variability in validation metrics is expected because of this fact, same model comparison conclusions can be derived in terms of $\mathrm{R}$ and $\mathrm{S}$ metrics. Therefore, stressing the importance of the previously commented issues (reanalysis soil moisture). It is worth mentioning here that in the new launch of LSASAF ET products the lack of $\lambda E_{I}$ is explicitly addressed by modulating the vegetation $r_{s}$ by a wet fraction term.

Apart from the above mentioned model limitations, it has to be taken into account that the resulting deviations between in-situ ET observations and modelled ET estimates result also from the contribution of other causes. In particular, it is worth noting the extra uncertainty introduced by the spatial mismatch between ground measurements and remote sensing data. Footprints for eddy covariance range from 0.1 to $0.5 \mathrm{~km}^{2}$ (Kljun et al., 2004) depending on the reference height. This scale is much smaller than the MODIS (or MERRA) pixel $1 \mathrm{~km}^{2}$ resolution. In addition, uncertainty in these remote sensing data will also introduce uncertainty in the modelled ET estimates. This uncertainty may be derived from an imperfect cloud masking and atmospheric correction of these data (Hilker et al., 2012; Gomis-Cebolla et al., 2018). Another cause of deviation to take into account is the uncertainty derived from the in-situ eddy-covariance measurements (lack of energy closure) and the possible deviations introduced by the selection of a specific correction method. As it was observed validation metrics (and therefore final conclusions) were dependent on the type of in-situ data (uncorrected or corrected) and the type of correction considered (BR or ER). Nevertheless, it is worth noting that same model comparison conclusions were derived from BR and ER (although with different validation metrics values).

\subsection{Forcing scenario II and spatial patterns}

Scenario II differs from scenario I in the use of reanalysis meteorological data for forcing the models. Reanalysis data uncertainty results from reanalysis inherent errors and the spatial mismatch between ground measurements. Quality of these data was addressed by comparison of reanalysis inputs against in-situ stations inputs. From Table 3, the poor quality of these data can be deduced. Generally, for the three reanalysis, wind speed was the most uncertain parameter with a greater than $60 \%$ of relative error (RE), followed by radiation inputs (approximately $30 \%$ ), humidity $(15 \%)$ and temperature inputs (maximum $\mathrm{RE}$ of $10 \%$ ). In addition, $\mathrm{R}$ values range from 0.3 to 0.7 for radiation, temperature and wind variables while for humidity variables a maximum value of 0.35 is obtained. The impact of these inputs uncertainty on model output was assessed using the Sobol global sensitivity analysis. From Fig. 5, it can be deduced that radiation inputs are the key variables driven model output, and therefore model uncertainty will result mainly from radiation input uncertainty. This fact, is clearly in agreement with the fact that the tropical forests of Amazonia are energy driven (Fisher et al., 2009; Rocha et al., 2009). In particular, for PT-JPL and SEBS model $\mathrm{Rn}_{24}$ is the key variable. A bias in these input will be therefore directly translated into a bias in the estimates. Considering the scaling logic of PET for PT-JPL and the assumption of constant evaporative fraction this result could be expected. In addition, this fact also explained the similarity in PT-JPL and SEBS results in scenario I. In the case of PM-Mu, model variability is mainly driven by $\mathrm{SR}_{\text {in }}$ variability. $A$ bias in $\mathrm{SR}_{\text {in }}$ translates into a direct bias in $\mathrm{Rn}$ and therefore in the estimates. It is worth mentioning the role played by $\mathrm{T}_{\mathrm{a}}$ and $e_{a}$ variables (especially from May to November). These inputs are involved in the calculation of VPD $\left(e_{s}\right.$ is derived from $\left.T_{a}\right)$. During these months, VPD increases therefore contributing more to $\lambda E$. In addition, $\mathrm{T}_{\mathrm{a}}$ is also involved in the calculation of Rn. For LSASAF, although $\mathrm{SR}_{\text {in }}$ explains most of the model variance, $\mathrm{e}_{\mathrm{a}}, \mathrm{T}_{\mathrm{a}}$ and Root $_{\mathrm{sm}}$ additionally play an important role. Taking into account model parametrization these results were expected. $\mathrm{e}_{\mathrm{a}}$ is involved in the $\lambda E$ calculation, explicitly (specific humidity) and implicitly (in the calculation of $r_{s}$ ). The same holds true for $\mathrm{T}_{\mathrm{a}}$ but for the sensible heat flux. Root $\mathrm{sm}_{\mathrm{s}}$ is used in $r_{s}$ calculation. Therefore, the effect of reanalysis inputs on model estimates is not as direct as in the other models. It is worth noting here, that model is almost insensitive to wind speed (even if it is the most 
uncertain input).

From Figs. 6 and 7 it is observed the negative impact these inputs have on model performance. It is observed that for some models (PMMu-ERA and LSASAF-MERRA) the biases introduced by model parametrization tend to cancel out when considering input forcing data with an opposite bias (i.e. the overestimation of in-situ ET values for PM-Mu is alleviated when considering a $\mathrm{SR}_{\mathrm{in}}$ that has a negative bias). This fact could explain the slight improvement observed for these models. Nevertheless, no particular combination stood out as the best performing one (Figs. 5 and 6). Taking into account the similarity in reanalysis radiation inputs, this result was somehow expected.

The effect of reanalysis biases in ET estimates is clearly deduced in Fig. 8. These biases are mainly explained by the biases in reanalysis radiation inputs. For PT-JPL, the positive bias in MERRA and GLDAS reanalysis explains the overestimation of in-situ forced results. The contrary is observed for ERA. For PM-Mu, the ERA and GLDAS underestimation observed correlates with the negative bias in $\mathrm{SR}_{\mathrm{in}}$. The best agreement provided by MERRA could be explained because the biophysical constants used in the model were calibrated considering this reanalysis data as input (Mu et al., 2011). For SEBS-GF the bias in $\mathrm{Rn}_{24}$ is directly translated into model estimates. For LSASAF, the biases observed in ET estimates could be explained mainly by the $\mathrm{SR}_{\text {in }}$ bias. Amongst reanalysis it was found that ERA provides a stronger seasonal behaviour than MERRA and GLDAS (Figs. 8 and 11). This fact is directly translated into ET temporal patterns. This results helps to confirm the suspicion that input data quality is more important than model quality in order to explain the results. This can also be deduced considering spatial patterns comparison (Fig. 9). Spatial discrepancy amongst different reanalysis is greater than amongst models that use the same reanalysis. In addition, the selection of a specific reanalysis explains the temporal variability (models differ in the absolute values provided). In agreement, with previous results it was observed that ET spatial patterns and temporal behaviour was leaded by radiation inputs (Figs. 911). Biases in these inputs translated directly into biases in ET estimates (same explanation of Fig. 8 applied here) and were able to explain maximum negative deviations greater than $500 \mathrm{~mm}$ /year for LSASAF using ERA and GLDAS reanalysis (the underestimation effect of LSASAF is increased by the negative bias of these reanalysis) and de-viations ranging between $\pm 500 \mathrm{~mm}$ /year for the rest of the models.

\section{Conclusions}

In this study, the ET estimates of four remote-sensing based algorithms (PT-JPL, PM-Mu, SEBS (SEBS-GF) and LSASAF) were validated over the tropical forests of the Amazonian region. Validation was performed using in-situ data forcing and reanalysis data forcing. MERRA-2, ERA-Interim and GLDAS-2 were used as a source of external meteorological input data. Main conclusions derived from this study are:

1 From the in-situ based validation, it was concluded that PT-JPL was the best performing model (RMSE $=0.55 \mathrm{~mm} /$ day, $\mathrm{R}=0.88$ ). The worst performance was provided by LSASAF, because of an underestimation resulting from ignoring water canopy evaporation. SEBS performance was similar to that of PT-JPL. Nevertheless, being dependent on LST observations, SEBS estimates are limited by the continuous cloud cover of the region. The gap-filling method proposed was shown to alleviate this issue, nevertheless it resulted in an underestimation of SEBS values. PM-Mu shows similar performance to PT-JPL and SEBS. Nevertheless it provided an inherent tendency to overestimate in-situ ET observations.

2 From reanalysis-based validation, it was concluded that the reanalysis poor data quality over the region determined the poor model performance observed. MERRA-2, ERA-Interim and GLDAS-2 contain biases that clearly impact model performance. In particular, the biases obtained in ET estimates derived by the biases on radiation inputs. MERRA-2 tends to overestimate daily net radiation and incoming solar radiation. ERA-Interim tends to underestimate both variables, and GLDAS tends to overestimate daily radiation while underestimating incoming solar radiation. Discrepancies amongst these inputs mainly explain discrepancies between models estimates (spatial and temporal patterns). The results obtained in this study, thus serve to emphasize the need to improve the accuracy of reanalysis estimates in order to improve the accuracy in ET estimates.

\section{Acknowledgments}

This study was supported by Ministerio de Educación, Cultura y Deporte (grant FPU14/06502) and Ministerio de Economía y Competitividad (PCIN 2015-232, ESP2015-71894-R). The authors thank MODIS and MAIAC data teams, MERRA-2, ERA-Interim and GLDAS-2 data teams and LBA program for making the data publicly available. We are also grateful to the valuable suggestions of the anonymous reviewer that helped to improve the study.

\section{Appendix A. Supplementary data}

Supplementary data associated with this article can be found, in the online version, at https://doi.org/10.1016/j.jag.2019.04.009.

\section{References}

Anderson, M.C., Norman, J.M., Mecikalski, J.R., Otkin, J.A., Kustas, W.P., 2007. A climatological study of evapotranspiration and moisture stress across the continental United States based on thermal remote sensing: 1. Model formulation. J. Geophys. Res. Atmos. 112 (D10).

Araujo, A.C., Nobre, A.D., Kruijt, B., Elbers, A., Dallorosa, R., Stefani, P., von Randow, C., Manazi, A.O., Culf, A.D., Gash, J.H.C., Valentini, R., Kabat, P., 2002. Comparative measurements of carbon dioxide fluxes from two nearby towers in a central Amazonian rainforest: the Manaus LBA site. J. Geophys. Res. 107. https://doi.org/10. 1029/2001JD000676.

Badgley, G., Fisher, J., Jiménez, C., Tu, K., Vinukollu, R., 2015. On uncertainty in global terrestrial evapotranspiration estimates from choice of input forcing datasets. J.

Hydrometeorol. 16 (4), 1449-1455. https://doi.org/10.1175/jhm-d-14-0040.1. Beljaars, A.C.M., Viterbo, P., 1994. The sensitivity of winter evaporation to the formulation of aerodynamic resistance in the ECMWF model. Boundary Layer Meteorol. 71 (1-2), 135-149.

Bosilovich, M.G., Lucchesi, R., Suarez, M., 2015. MERRA-2: File Specification. Broxton,

P.D., Zeng, X., Scheftic, W., Troch, P.A., 2014. A MODIS-based $1 \mathrm{~km}$ maximum green vegetation fraction dataset. J. Appl. Meteorol. Clim. https://doi.org/10.1175/ JAMC-D-13-0356.1.

Brutsaert, W., 1999. Aspects of bulk atmospheric boundary layersimilarity under freeconvective conditions. Rev. Geophys. 37, 439-451.

Brutsaert, W., 2005. Hydrology: an Introduction. Cambridge University Press. Brutsaert,

W., 2013. Evaporation into the Atmosphere: Theory, History and Applications Vol. 1 Springer Science \& Business Media.

Campbell, G., Norman, J., 1998. Introduction to Environmental Biophysics. Springer, New York.

Carswell, F.E., Costa, A.L., Palheta, M., Malhi, Y., Meir, P., Costa, J.D.R., Ruivo, M.D., Leal, L.D.M., Costa, J.M.N., Clement, R.J., Grace-, J., 2002. Seasonality in CO2 and $\mathrm{H} 2 \mathrm{O}$ flux at an eastern Amazonian rain forest. J. Geophys. Res. 107 (D20), 8076. https://doi.org/10.1029/2000JD000284.

Cox, P., Betts, R., Jones, C., Spall, S., Totterdell, I., 2000. Erratum: acceleration of global warming due to carbon-cycle feedbacks in a coupled climate model. Nature 408 (6813) pp.750-750

Dee, D.P., Uppala, S.M., Simmons, A.J., Berrisford, P., Poli, P., Kobayashi, S., et al., 2011 The ERA-interim reanalysis: configuration and performance of the data assimilation system. Q. J. R. Meteorol. Soc. 137 (656), 553-597.

Ershadi, A., McCabe, M.F., Evans, J.P., Chaney, N.W., Wood, E.F., 2014. Multi-site evaluation of terrestrial evaporation models using FLUXNET data. Agric. For. Meteorol. 187, 46-61.

FAO/IIASA/ISRIC/ISSCAS/JRC, 2012. Harmonized World Soil Database (Version 1.2). FAO, Rome, Italy and IIASA, Laxenburg, Austria.

Fisher, J.B., Debiase, T.A., Qi, Y., Xu, M., Goldstein, A.H., 2005. Evapotranspiration models compared on a Sierra Nevada forest ecosystem. Environ. Modell. Softw. 20, 783-796.

Fisher, J.B., Tu, K.P., Baldocchi, D.D., 2008. Global estimates of the land atmosphere water flux based on monthly AVHRR and ISLSCP-II data, validated at 16 FLUXNET sites. Remote Sens. Environ. 112, 901-919.

Fisher, J.B., Malhi, Y., Bonal, D., Da Rocha, H.R., De Araujo, A.C., Gamo, M., et al., 2009. The land-atmosphere water flux in the tropics. Global Change Biol. 15 (11), 2694-2714.

García, M., Sandholt, I., Ceccato, P., Ridler, M., Mougin, E., Kergoat, L., et al., 2013. Actual evapotranspiration in drylands derived from in-situ and satellite data: asses-sing biophysical constraints. Remote Sens. Environ. 131, 103-118. https:// doi.org/ 
10.1016/j.rse.2012.12.016.

Ghilain, N., Arboleda, A., Gellens-Meulenberghs, F., 2011. Evapotranspiration modelling at large scale using near-real time MSG SEVIRI derived data. Hydrol. Earth Syst. Sci. 15 (3)

Gibson, L.A., Münch, Z., Engelbrecht, J., 2011. Particular uncertainties encountered in using a pre-packaged SEBS model to derive evapotranspiration in a heterogeneous study area in South Africa. Hydrol. Earth Syst. Sci. 15 (1), 295-310.

Gomis-Cebolla, J., Jimenez, J., Sobrino, J., 2018. LST retrieval algorithm adapted to the Amazon evergreen forests using MODIS data. Remote Sens. Environ. 204, 401-411. https://doi.org/10.1016/j.rse.2017.10.015.

Goulden, M.L., Miller, S.D., Rocha, H.R., Menton, M.C., Freitas, H.C., Figueira, A.M.S., Sousa, C.A.D., 2004. Diel and seasonal patterns of tropical forest $\mathrm{CO} 2$ exchange. Ecol. Appl. 14, 42-54. https://doi.org/10.1890/02-6008.

Harper, A., Baker, I., Denning, A., Randall, D., Dazlich, D., Branson, M., 2014. Impact of evapotranspiration on dry season climate in the Amazon Forest*. J. Clim. 27 (2), 574-591.

Hilker, T., Lyapustin, A., Tucker, C., Sellers, P., Hall, F., Wang, Y., 2012. Remote sensing of tropical ecosystems: atmospheric correction and cloud masking matter. Remote Sens. Environ. 127, 370-384.

Hutyra, L.R., Munger, J.W., Saleska, S.R., Gottlieb, E., Daube, B.C., Dunn, A.L., Amaral, D.F., Camargo, P.B., Wofsy, S.C., 2007. Seasonal controls on the exchange of carbon and water in an Amazonian rain forest. J. Geophys. Res. Biogeosci. 112, 1-16. https://doi.org/10.1029/2006JG000365.

Jarvis, P.G., 1976. The interpretation of the variations in leaf water potential and stomatal conductance found in canopies in the field. Philos. Trans. R. Soc. Lond. B 593-610.

Kljun, N., Calanca, P., Rotach, M., Schmid, H., 2004. A simple parameterisation for flux footprint predictions. Boundary-Layer Meteorol. 112, 503-523. https://doi.org/10. 1023/b:boun.0000030653.71031.96

Li, F., Kustas, W.P., Anderson, M.C., Prueger, J.H., Scott, R.L., 2008. Effect of remote sensing spatial resolution on interpreting tower-based flux observations. Remote Sens. Environ. 112, 337-349. https://doi.org/10.1016/j.rse.2006.11.032.

Malhi, Y., Roberts, J., Betts, R., Killeen, T., Li, W., Nobre, C., 2008. Climate change, deforestation, and the fate of the Amazon. Science 319, 169-172.

Malhi, Y., 2011. The productivity, metabolism and carbon cycle of tropical forest vegetation. J. Ecol. 100 (1), 65-75.

Martens, B., Miralles, D.G., Lievens, H., van der Schalie, R., de Jeu, R.A.M., Fernández Prieto, D., Beck, H.E., Dorigo, W.A., Verhoest, N.E.C., 2017. GLEAM v3: satellitebased land evaporation and root-zone soil moisture. Geosci. Model Dev. 10, 1903-1925. https://doi.org/10.5194/gmd-10-1903-2017.

Miralles, D.G., Holmes, T.R.H., de Jeu, R.A.M., Gash, J.H., Meesters, A.G.C.A., Dolman, A.J., 2011. Global land-surface evaporation estimated from satellite-based observations. Hydrol. Earth Syst. Sci. 15, 453-469. https://doi.org/10.5194/ hess-15-453-2011.

Monteith, J.L., 1965. Evaporation and environment. Symp. Soc. Exp. Biol. 19, 205-224

Mu, Q.Z., Zhao, M.S., Running, S.W., 2011. Improvements to a MODIS global terrestrial evapotranspiration algorithm. Remote Sens. Environ. 115, 1781-1800.

Myneni, R.B., Yang, W., Nemani, R.R., Huete, A.R., Dickinson, R.E., Knyazikhin, Y., Didan, K., Fu, R., Juarez, R.I.N., Saatchi, S.S., Hashimoto, H., Ichii, K., Shabanov, N.V., Tan, B., Ratana, P., Privette, J.L., Morisette, J.T., Vermote, E.F., Roy, D.P., Wolfe, R.E., Friedl, M.A., Running, S.W., Votava, P., El-Saleous, N., Devadiga, S., Su, Y., Salomonson, V.V., 2007. Large seasonal swings in leaf area of Amazon rainforests. PNAS 104, 4820-4823.

Priestley, C.H.B., Taylor, R.J., 1972. On the assessment of surface heat flux and evaporation using large-scale parameters. Mon. Weather Rev. 100, 81-92.

Reichle, R., Koster, R., De Lannoy, G., Forman, B., Liu, Q., Mahanama, S., Toure, A., 2011. Assessment and enhancement of MERRA land surface hydrology estimates. J. Clim. 924 (24), 6322-6338. https://doi.org/10.1175/JCLI-D-10-05033.1.

Rocha, H.R., Manzi, A.O., Cabral, O.M.R., Miller, S.D., Goulden, M.L., Saleska, S.R., Coupe, N.R., Wofsy, S.C., Borma, L.S., Artaxo, P., Vourlitis, G.L., Nogueira, J.S., Cardoso, F.L., Nobre, A.D., Kruijt, B., Freitas, H.C., von Randow, C., Aguiar, R.G., Maia, J.F., 2009. Patterns of water and heat flux across a biome gradient from tropical forest to savanna in Brazil. J. Geophys. Res. 114, 1-8. https://doi.org/10.1029/
2007JG000640.

Rodell, M., Houser, P.R., Jambor, U., Gottschalck, J., Mitchell, K., Meng, C.-J., Arsenault, K., Cosgrove, B., Radakovich, J., Bosilovich, M., Entin, J.K., Walker, J.P., Lohmann, D., Toll-, D., 2004. The global land data assimilation system. Bull. Am. Meteorol. Soc 85 (3), 381-394.

Saleska, S.R., da Rocha, H.R., Huete, A.R., Nobre, A.D., Artaxo, P., Shimabukuro, Y.E., 2013. LBA-ECO CD-32 Flux Tower Network Data Compilation, Brazilian Amazon: 1999-2006. Data set, available at:. from Oak Ridge National Laboratory Distributed Active Archive Center, Oak Ridge, Tennessee, USA. https://doi.org/10.3334/ ORNLDAAC/1174. http://daac.ornl.gov.

Saltelli, A., Annoni, P., Azzini, I., Campolongo, F., Ratto, M., Tarantola, S., 2010. Variance based sensitivity analysis of model output. Design and estimator for the total sensitivity index. Comput. Phys. Commun. 181, 259-270.

Simard, M., Pinto, N., Fisher, J.B., Baccini, A., 2011. Mapping forest canopy height globally with spaceborne lidar. J. Geophys. Res. Biogeosci. 116 (G4)

Sobol, I.M., 2001. Global sensitivity indices for nonlinear mathematical models and their Monte Carlo estimates. Math. Comput. Simul. 55 (1-3), 271-280. https://doi.org/10. 1016/S0378-4754(00)00270-6.

Sobrino, J.A., Jiménez-Muñoz, J.C., Soria, G., Gomez, M., Barella Ortiz, A., Romaguera, M., Zaragoza, M., Julien, Y., Cuenca, J., Atitar, M., Hidalgo, V., Franch, B., Mattar, C. Ruescas, A., Morales, L., Gillespie, A., Balick, L., Su, Z., Nerry, F., Peres, L., Libonati, R., 2008. Thermal remote sensing in the framework of the SEN2FLEX project: field measurements, airborne data and applications. Int. J. Remote Sens. 29, 4961-4991.

Su, Z., Schmugge, T., Kustas, W.P., Massman, W.J., 2001. An evaluation of two models for estimation of the roughness height for heat transfer between the land surface and the atmosphere. J. Appl. Meteorol. 40, 1933-1951.

$\mathrm{Su}, \mathrm{Z}$., 2002. The surface energy balance system (SEBS) for estimation of turbulent heat fluxes. Hydrol. Earth Syst. Sci. 6 (1), 85-100. https://doi.org/10.5194/ hess-6-85-2002.

Taylor, K.E., 2001. Summarizing multiple aspects of model performance in a single diagram. J. Geophys. Res. 106 (D7), 7183-7192.

Timmermans, J., Su, Z., van der Tol, C., Verhoef, A., Verhoef, W., 2013. Quantifying the uncertainty in estimates of surface-atmosphere fluxes through joint evaluation of the

SEBS and SCOPE models. Hydrol. Earth Syst. Sci. 17, 1561-1573.

Twine, T.E., Kustas, W.P., Norman, J.M., et al., 2000. Correcting eddy-covariance flux underestimates over a grassland. Agric. For. Meteorol. 103, 279-300.

Van den Hurk, B.J., Viterbo, P., Beljaars, A.C.M., Betts, A.K., 2000. Offline Validation of the ERA40 Surface Scheme (P. 43). European Centre for Medium-Range Weather Forecasts.

Van der Kwast, J., Timmermans, W., Gieske, A., Su, Z., Olioso, A., Jia, L., Elbers, J., Karssenberg, D., de Jong, S., 2009. Evaluation of the surface energy balance system (SEBS) applied to ASTER imagery with flux-measurements at the SPARC 2004 site (Barrax, Spain). Hydrol. Earth Syst. Sci. 13, 1337-1347.

Vinukollu, R., Meynadier, R., Sheffield, J., Wood, E., 2011. Multi-model, multi-sensor estimates of global evapotranspiration: climatology, uncertainties and trends. Hydrol.

Process. 25 (26), 3993-4010. https://doi.org/10.1002/hyp.8393.

Von Randow, C., Manzi, A.O., Kruijt, B., et al., 2004. Comparative measurements and seasonal variations in energy and carbon exchange over forest and pasture in South West Amazonia. Theor. Appl. Climatol. 78, 5-26.

Wagner, F.H., Herault, B., Rossi, V., Hilker, T., Maeda, E.E., Sanchez, A., Lyapustin, A.I., Galvão, L.S., Wang, Y., Aragão, L.E.O.C., 2017. Climate drivers of the Amazon forest greening. PLOS One 12, e01800932. https://doi.org/10.1371/journal.pone. 0180932.

Werth, D., Avissar, R., 2002. The local and global effects of Amazon deforestation. J. Geophys. Res.-Atmos. 107, 8087.

Yao, Y., Liang, S., Li, X., Chen, J., Liu, S., Jia, K., et al., 2017. Improving global terrestrial evapotranspiration estimation using support vector machine by integrating three process-based algorithms. Agric. For. Meteorol. 242, 55-74. https://doi.org/10. 1016/j.agrformet.2017.04.011.

Yuan, W.P., Liu, S.G., Yu, G.R., Bonnefond, J.M., Chen, J.Q., Davis, K., et al., 2010. Global estimates of evapotranspiration and gross primary production based on MODIS and global meteorology data. Remote Sens. Environ. 114, 1416-1431. 